\title{
LAS JUVENTUDES POPULARES MEXICANAS FRENTE A LA COVID-19: ESTIGMAS, APREMIOS Y PRÁCTICAS DE PREVENCIÓN
}

\author{
MinOR MORA SALAS ${ }^{1}$ \\ Gustavo URBInA CORTÉS ${ }^{2}$
}

\begin{abstract}
RESUMEN
En este artículo se analiza el comportamiento de los sectores juveniles de extracción popular frente a las medidas preventivas impulsadas para lidiar con la pandemia de Covid-19 en la Ciudad de México (CDMX). Particularmente, nos interesa preguntarnos en qué medida la población joven constituye un grupo atípico respecto a las prácticas sociales y sanitarias que resultan más efectivas para prevenir el contagio, así como para romper la cadena de transmisión de esta enfermedad. Mediante un análisis de la pauta de propagación y la aplicación de una encuesta en sectores urbanos de alta marginación, mostramos que, contrario de la creencia general, persiste una escasa diferencia en el comportamiento prevalente entre jóvenes y adultos.
\end{abstract}

PALABRAS CLAVES: COVID-19, PREVENCIÓN, JÓVENES.

\footnotetext{
${ }^{1}$ Doctor en Ciencia Social con especialidad en Sociología. Profesor-investigador, Centro de Estudios Sociológicos, El Colegio de México. Correo electrónico: mimora@colmex.mx

${ }^{2}$ Doctor en Ciencia Social con especialidad en Sociología. Profesor-investigador, Centro de Estudios Sociológicos, El Colegio de México. Correo electrónico: gaurbina@colmex.mx
} 


\title{
AS JUVENTUDES MEXICANAS DE SETORES POPULARES ANTE A COVID-19: ESTIGMAS, URGÊNCIAS E PRÁTICAS DE PREVENÇÃO
}

\begin{abstract}
RESUMO
Este artigo analisa o comportamento dos jovens de setores populares em relação às medidas preventivas promovidas para lidar com a pandemia COVID-19 na Cidade do México (CDMX). Em particular, estamos interessados em questionar em que medida a população jovem constitui um grupo atípico em relação às práticas sociais e sanitárias que resultam mais eficazes para prevenir o contágio, bem como para quebrar a cadeia de transmissão desta doença. Através de uma análise do padrão de propagação e da aplicação de uma pesquisa em setores urbanos altamente marginalizados, mostramos que, ao contrário da crença geral, persiste uma escassa diferença no comportamento prevalente entre jovens e adultos.
\end{abstract}

PALAVRAS-CHAVE: COVID-19, PREVENÇÃO, JOVENS.

\section{MEXICAN YOUTHS FROM WORKING-CLASS BACKGROUNDS FACING COVID-19: STIGMAS, URGENCIES AND PREVENTION PRACTICES}

\begin{abstract}
This article analyzes the behavior of young people from working-class backgrounds in the face of COVID-19 preventive measures in Mexico City (CDMX), particularly on to what extent the young population constitutes an atypical group regarding the most effective social and sanitary practices to both avoid COVID-19 contagion and break its chain of infection. From the analysis of propagation patterns and a survey conducted on highly marginalized urban communities, we show that, contrary to the popular belief, there is a small difference between the prevalent behavior of young people and adults.
\end{abstract}

KEYWORDS: COVID-19, PREVENTION, YOUNG PEOPLE. 


\section{INTRODUCCIÓN}

En este artículo se analiza el comportamiento de los sectores juveniles de extracción popular frente a las medidas preventivas impulsadas por las autoridades para lidiar con la pandemia de la Covid-19 en la Ciudad de México (CDMX). Particularmente, nos interesa preguntarnos en qué medida la población joven constituye un grupo atípico con respecto a las prácticas sociales y sanitarias que resultan más efectivas para prevenir el contagio, así como para romper la cadena de transmisión de esta enfermedad.

Para responder esta pregunta centramos el análisis en tres aspectos. El primero está relacionado con la pauta de propagación de este virus entre diferentes grupos etarios, a modo de indagar si el riesgo de exposición de la población joven difiere del observado entre la población adulta. El segundo alude a la preminencia de un discurso público de responsabilidad social, el cual estigmatiza a las y los jóvenes al presentarlos como personas negligentes en el acatamiento de las principales recomendaciones de prevención y salvaguarda de la salud. Finalmente, el tercero se refiere a la tensión entre la esperada asunción de cautelas y las posibilidades reales para mantenerlas durante períodos prolongados de tiempo.

Con el propósito de contrastar lo anterior, nos referiremos a las/os jóvenes como aquellas personas situadas en un rango etario comprendido entre 18 y 35 años. Distanciándonos de las nociones institucionalistas que delimitan este grupo en el tramo de 15 a 24 (OIJ, 2008) o que lo extienden hasta los 29 años (IMJUVE, 2017), aquí optamos por aprehender una concepción extendida de la juventud, comprendiendo que los márgenes de autonomía y de adquisición de 
responsabilidades no siempre son susceptibles de ser acotados en umbrales exactos de edad (Furlong y Cartmel, 2007) ${ }^{3}$.

Este trabajo abreva de tres recursos. El primero está constituido por el análisis de la dinámica de propagación de la Covid-19 en la CDMX, teniendo en cuenta que, hasta el 31 de enero de 2021, dicha entidad aglutinaba hasta el $26 \%$ de los casos acumulados a nivel nacional (SISVER, 2021). El segundo se enfoca en el contraste entre la información difundida por las autoridades del gobierno y los hábitos preventivos asumidos entre una muestra situada de jóvenes en la CDMX. El tercero problematiza las prácticas de cuidado de los sectores juveniles más carenciados, teniendo en cuenta las privaciones agudas que ponen en entredicho la posibilidad de romper con las cadenas de contagio del virus SARSCoV-2.

De acuerdo con datos del Censo 2020 (INEGI, 2021), los contingentes de entre 15 y 34 años constituyen alrededor de una tercera parte de la totalidad de habitantes tanto a nivel nacional $(32,3 \%)$ como en la $\operatorname{CDMX}(31,1 \%)$. Con necesidades altamente diferenciadas en materia educativa, ocupacional $\mathrm{y}$ familiar, este subconjunto demográfico representa un enorme desafío para gestionar la dinámica de la pandemia tanto como sus consecuencias.

Mediante este trabajo pretendemos mostrar que la mitigación de la crisis sanitaria pasa no solo por el reconocimiento de la dinámica epidemiológica. También es indispensable incorporar una mirada socialmente informada que tome en cuenta las particularidades de los grupos con mayores necesidades socioeconómicas. Asimismo, buscamos problematizar las narrativas que tienden a presentar a la población joven como un contingente socialmente indiferenciado

\footnotetext{
${ }^{3}$ Para propósitos estadísticos y dependiendo de la fuente de información, en ocasiones presentaremos cotejos por grupos quinquenales o por conjuntos delimitados según etapas vitales. En este último caso, distinguiremos como jóvenes a las personas de hasta 35 años de edad, subdividiendo a las adultas en un subgrupo de entre 36 y 55 y otro de 56 y más años. Estos subconjuntos resultan también consistentes con las pautas de comportamiento que se exploran en torno a la Covid-19.
} 
que, de manera irresponsable, asume conductas de riesgo, contribuyendo, de esta manera, a mantener activas las cadenas de transmisión de este virus.

\section{COORDENADAS CENTRALES DE LA DISCUSIÓN SOBRE COVID-19 Y JÓVENES}

Ha transcurrido más de un año desde la detección del primer paciente infectado con el virus SARS-CoV-2 en Wuhan, China. De noviembre del 2019 a la fecha, el mundo cuenta con un importante caudal de información sobre algunas de las especificidades y los desafíos ocasionados por la irrupción de la pandemia por Covid-19. No obstante, contrario al abundante conocimiento en materia epidemiológica, todavía sabemos muy poco sobre las principales pautas conductuales y sociales de cara a la enfermedad.

Además de las características asociadas a la transmisión, los cuadros clínicos y sus posibles vías de tratamiento, las circunstancias sociales propicias para la propagación del virus aún están sujetas a una acalorada discusión. Como bien sugiere Daniel Feierstein (2021), está claro que las conjugaciones económicas y políticas de la crisis sanitaria reportan efectos en las disputas por las representaciones de lo acontecido.

Con resonancias que trascienden la especificidad del caso argentino, el análisis de Feierstein (2021) muestra que las medidas asumidas por las autoridades no siempre logran aparejar el curso de los hechos con la emisión anticipada de juicios. Este autor constata que una buena parte de las posturas discursivas con implicaciones de política pública aparecen motivadas por criterios apresurados, cuando no desinformados, ante la novedad, el desconocimiento y la confusión propiciados por la emergencia de un nuevo virus. 
La situación no difiere cuando se habla de la relación entre los grupos poblacionales jóvenes y la gestión de la pandemia. Como preámbulo a nuestro trabajo, sostenemos que ese vínculo está estructurado en torno a tres inercias.

La primera está relacionada con el carácter adultocéntrico de las estrategias de comunicación y, por ende, con la construcción de la Covid-19 como problema público. Ante la acentuada tendencia a la hospitalización y a una mayor propensión de gravedad con potenciales resultados fatales entre los grupos poblacionales de la tercera edad - mayores de 60 años-, las juventudes han figurado como un referente deficientemente situado en la discusión. Casi de manera anecdótica, las personas jóvenes han sido señaladas constantemente por su presunta irresponsabilidad y su renuencia a acatar el llamado de las autoridades para seguir cabalmente con las principales prácticas preventivas de contagio. Similar a lo que Araya et al. (2020) detallan para el caso chileno, en muchos otros contextos, la población joven es usualmente aludida como protagonista de fiestas, concurrencias sociales o llana displicencia; al tiempo que se ignora o minimiza la participación de la población adulta en eventos masivos de carácter festivo, religioso, político y cultural.

No obstante, como bien apuntan Chauvin et al. (2020), los contingentes juveniles constituyen un sector demográfico expuesto a riesgos diferenciados según su contexto de ubicación. A diferencia de los países de altos ingresos, en los países en desarrollo no solo persisten altas tasas de infección juvenil, sino que, a su vez, prevalece una menor posibilidad de lograr una recuperación oportuna en caso de contraer la Covid-19. Con sistemas de salud más precarios y segmentados, las y los jóvenes de países como Colombia y México tienen hasta el doble de probabilidades de hospitalización y de fallecimiento, en contraste con quienes residen en lugares como Estados Unidos y Canadá (Chauvin et al., 2020).

Una segunda inercia está dada por la escasa atención prestada al vínculo entre conductas, percepciones de riesgo y prácticas sociales que envuelven a las 
juventudes. Con importantes repuntes de contagios entre la población juvenil latinoamericana (OPS, 2020), persiste la incógnita sobre las configuraciones sociales que, más allá de la conducta personal, conducen a patrones de propagación con mayor incidencia entre los segmentos juveniles. Asumir a la displicencia como factor explicativo unívoco de la creciente tasa de infección, implica dar por sentado que la vasta mayoría de las y los jóvenes cuenta con condiciones favorables para acatar los confinamientos -forzados o voluntarios - y para suspender la vida cotidiana con costes mínimos.

Finalmente, una tercera cuestión está referida a la estigmatización de los sectores populares. Si bien la retórica política ha hecho énfasis en las adversidades de los grupos vulnerables, la sobrada insistencia en la responsabilidad social ha derivado en señalamientos particulares donde se culpabiliza a las personas por la asunción de riesgos innecesarios en el contexto de la pandemia. En el juego de los prejuicios, trabajos como los de Bagcchi (2020), Moctezuma (2020) y Logie y Turan (2020) han observado que la construcción de la otredad pasa por un tamizaje del riesgo social frente a la amenaza viral. El personal de salud, las/os migrantes, la población trabajadora que no puede laborar desde casa y, desde luego, las/os jóvenes forman parte de este cúmulo, donde precisamente los sectores subalternos ocupan un papel primordial. Sin consideraciones amplias sobre las limitaciones que impone una vida sujeta a diferentes privaciones, contribuciones como las de Machado da Silva et al. (2020) en Brasil y Sánchez (2020) en México sugieren que la desinformación pública, la cobertura mediática y las pautas selectivas de infección tienden a categorizar negativamente a las familias con mayor estrechez económica.

En el ya citado trabajo de Araya et al. (2020), encontramos algunas reflexiones sobre la mirada estigmatizante que suele verterse sobre las juventudes más carenciadas, toda vez que se las asocia, sin evidencia empírica confiable, con 
menores precauciones sanitarias, mayor libertinaje en la prosecución de la vida social y menor apego al orden y las reglas establecidas. Tanto en los medios de comunicación, como en las redes sociales, persiste el sensacionalismo denunciante de las reuniones y concurrencias en colonias populares, omitiendo que otros estratos sociales también incurren en el relajamiento de las medidas de prevención. Con mayores recursos para administrar la desobediencia sanitaria y un repertorio de opciones más exclusivas y disimuladas para incurrir en la indisciplina, las juventudes más privilegiadas despliegan un conjunto de prácticas sociales que escapa a la vista de los medios de comunicación.

A modo de contrarrestar algunos de los vacíos producidos por esas tres inercias, previamente señaladas, en este trabajo pretendemos problematizar evidencia empírica que nos permita sopesar hasta qué punto el comportamiento de las juventudes difiere respecto del de otros grupos etarios. Asimismo, pretendemos contrastar las circunstancias y prácticas de prevención y autocuidado frente a la Covid-19 adoptadas por jóvenes de extracción popular en la CDMX. Frente a la centralidad conferida a la responsabilidad social y el señalamiento de irresponsabilidad que pesa sobre los contingentes juveniles, ofrecemos una mirada que pone en entredicho el carácter lineal de la elección entre la obediencia o el desacatamiento de las principales medidas de salvaguarda en el contexto de pandemia.

\section{Apuntes Metodológicos}

Para satisfacer los propósitos de este trabajo optamos por dos estrategias. La primera está dada por la problematización de la pauta de propagación de la Covid-19 en la CDMX. La segunda, por el análisis de una encuesta sobre percepciones sociales y prácticas de prevención frente a la Covid-19 en polígonos urbanos de alta marginación. 
Desde etapas relativamente anticipadas del desarrollo de la pandemia, la CDMX se consolidó como uno de los principales epicentros de contagio en el país. A inicios del 2021, dicha entidad concentraba cerca de una cuarta parte del total de contagios acumulados en México (SISVER, 2021). Sin una pauta que necesariamente refleje los ritmos y circunstancias de transmisión regional, el caso capitalino brinda pistas importantes sobre la magnitud y distribución de la incidencia del virus SARS-CoV-2.

Con el propósito de situar las principales distinciones entre los sectores poblacionales jóvenes y los contingentes demográficos de mayor edad, realizamos un análisis sobre la distribución de casos positivos de Covid-19 al interior de la CDMX. Mediante el cotejo por grupos etarios destacamos algunos de los rasgos detectados entre los casos diagnosticados con infección. Asimismo, establecemos algunos contrastes referentes a la evolución de la enfermedad, centrando la comparación en el tipo de tratamiento requerido (ambulatorio u hospitalización), así como en la distribución de decesos por confirmación o sospecha de positividad al virus SARS-CoV-2.

Los datos empleados en este análisis provienen de dos fuentes. La primera de ellas está dada por información del Sistema de Vigilancia Epidemiológica de Enfermedades Respiratorias (SISVER, 2021) del Gobierno Federal, cuya plataforma contiene el historial de incidencia y las características sociodemográficas principales de las personas oficialmente evaluadas como casos negativos, positivos o sospechosos de Covid-19. La segunda está constituida por el acervo de actas de defunción consignadas ante el Registro Civil del gobierno capitalino (SEDESA, 2021a) que, en colaboración con la Secretaría de Salud local, contiene el historial de fallecimientos confirmados o por sospecha de SARS-CoV-2.

Al igual que en el resto del país, la CDMX se ha conducido bajo el parámetro establecido por la autoridad federal en materia de salud. De ese modo, 
del 23 de marzo al 30 de mayo de 2020 tuvo lugar la llamada Jornada Nacional de Sana Distancia (JNSD), la cual implicó la interrupción de las labores escolares, las actividades productivas consideradas «no esenciales» y la celebración de eventos masivos bajo un llamado generalizado al confinamiento voluntario. Posterior a ese período, devino la etapa denominada como «Nueva Normalidad». Por esta última, las autoridades de salud hacían referencia a la regulación de actividades sociales, laborales, económicas, educativas y culturales de conformidad con la pauta regional de incidencia de casos positivos. Con ello, las medidas de mitigación pasarían a ser determinadas por los gobiernos estatales a partir de la implementación de un Semáforo de Riesgo Epidemiológico de cuatro colores: verde (bajo riesgo), amarillo (riesgo medio), naranja (riesgo alto) y rojo (máximo riesgo).

Al 30 de diciembre de 2020, la CDMX ostentaba una cifra de 320.251 contagios, constitutivos de poco menos del $23 \%$ de casos acumulados a nivel nacional (SISVER, 2021). De ese total, el 28,2\% se hallaba concentrado en dos alcaldías que, hasta la fecha, encabezan el listado de demarcaciones con mayor afectación a nivel local y nacional. Al cierre del año, Iztapalapa contaba con 49.932 casos acumulados, mientras que Gustavo A. Madero (GAM) alcanzaba la cifra de 40.571 registros (SISVER, 2021) ${ }^{4}$.

Estas alcaldías también culminaron el año como las dos zonas urbanas con el mayor número de decesos asociados a la Covid-19. Con tasas de letalidad cercanas al 7\%, al 30 de diciembre del 2020, GAM acumulaba 2.974 fallecimientos, mientras que en Iztapalapa dicha cifra llegaba a las 3.379 defunciones (SISVER, 2021).

${ }^{4}$ Cifras según el tabulador de registros de enero 2021. Los datos pueden variar ligeramente en virtud de la actualización permanente del Sistema de Vigilancia Epidemiológica. 
En un contexto signado por tasas de ocupación informal del $47 \%$ en la CDMX (INEGI, 2021), las dos alcaldías, previamente señaladas como epicentros de contagio, se caracterizan por importantes asimetrías en los niveles de calidad de vida. Mientras en Iztapalapa el $71 \%$ de sus unidades territoriales ostentan grados bajos y muy bajos de desarrollo social, en GAM dicha situación se presenta en el 49\% de sus polígonos constitutivos (Evalúa-DF, 2010) ${ }^{5}$.

Con ese telón de fondo, una segunda estrategia consistió en la aplicación de un cuestionario de encuesta a una muestra situada en dos polígonos urbanopopulares de las demarcaciones en comento y con altos grados de propagación del virus SARS-CoV-2. El primero tuvo cobertura en las colonias San Felipe de Jesús y Nueva Atzacoalco en la alcaldía GAM. El segundo estuvo integrado por residentes de las colonias San Lorenzo Tezonco y Lomas de San Lorenzo en la alcaldía Iztapalapa.

Con el objetivo de contrastar las prácticas y circunstancias de preservación de la salud, entre personas jóvenes y adultas pertenecientes a sectores socialmente desaventajados, optamos por una estrategia de muestreo probabilístico polietápico, orientada a la captación de informantes directos con domicilio en tales localidades, con un nivel de confianza al 95\% y un margen de error del $\pm 3 \%$. Cabe señalar que las cuatro territorialidades bajo escrutinio están clasificadas como colonias con muy altos grados de marginación, de conformidad con los datos de la Secretaría de Inclusión y Bienestar Social (SIDESO, 2020) del gobierno capitalino.

El período de recopilación de registros se suscitó durante la declaración de retorno al semáforo rojo por parte del gobierno capitalino, con tasas de

\footnotetext{
${ }^{5}$ Cabe aclarar que la CDMX está dividida, administrativamente, en dieciséis alcaldías, cada una de ellas subdividida en colonias, las cuales constituyen unidades territoriales o polígonos básicos de distribución residencial.
} 
ocupación hospitalaria superiores al 70\% en la CDMX, y un nuevo cierre de actividades económicas desde el 18 de diciembre de 2020.

Se obtuvieron 366 registros, 180 de residentes en GAM y 186 en Iztapalapa, todos ellos focalizados en las/os principales perceptoras/es de ingresos en el hogar. Los rasgos recabados son de la persona entrevistada al momento de aplicación de la encuesta, la cual consta de siete módulos de información basados en preguntas cerradas.

CuAdro 1. COMPOSICIÓN GENERAL DE LA MUESTRA (\%)

\begin{tabular}{|c|c|c|c|c|c|}
\hline \multirow{2}{*}{\multicolumn{2}{|c|}{ Rasgos principales }} & \multicolumn{4}{|c|}{ Grupos de edad } \\
\hline & & Hasta 35 & 36 a 55 & 56 y más & Total \\
\hline \multirow{2}{*}{ Polígono } & GAM & 50,0 & 48,2 & 51,0 & 49,2 \\
\hline & Iztapalapa & 50,0 & 51,8 & 49,0 & 50,8 \\
\hline \multirow{2}{*}{ Sexo } & Hombre & 44,3 & 44,5 & 41,2 & 44,0 \\
\hline & Mujer & 55,7 & 55,5 & 58,8 & 56,0 \\
\hline \multirow{3}{*}{ Escolaridad } & Hasta secundaria o menos & 32,3 & 34,0 & 33,3 & 33,3 \\
\hline & Hasta bachillerato & 46,0 & 54,5 & 54,9 & 51,7 \\
\hline & Hasta superior & 21,7 & 11,5 & 11,8 & 15,0 \\
\hline \multirow{5}{*}{ Ocupación } & Cuentapropista & 37,1 & 38,7 & 15,7 & 35,0 \\
\hline & Dueño/a de negocio o local & 28,2 & 26,2 & 13,7 & 25,1 \\
\hline & Asalariado/a & 25,0 & 19,9 & 7,8 & 20,0 \\
\hline & Pensionado/a & 0,0 & 0,0 & 51,0 & 7,1 \\
\hline & Desempleado/a & 9,7 & 15,2 & 11,8 & 12,8 \\
\hline
\end{tabular}

Fuente: Elaboración propia.

La muestra está integrada por un 33,9\% de casos de hasta 35 años; 52,2\% de entre 36 y 55 años; y un 13,9\% de 56 y más años. Como se aprecia en el cuadro 1, el único sesgo preponderante se presenta en el esquema de ocupación de personas de la tercera edad, donde las propias condiciones de levantamiento indujeron una baja captación de informantes ajenos/as a la circunstancia de retiro laboral. No obstante, dada la centralidad del contraste entre jóvenes y adultos en este trabajo, su efecto se considera marginal en la calidad de la información. 
Para los propósitos del artículo se elaboraron dos índices: uno sobre la frecuencia de acciones preventivas frente a la Covid-19 y otro sobre la disponibilidad de recursos y facilidades para afrontar la pandemia. Con base en reactivos constituidos por variables ordinales, se optó por la técnica de análisis factorial bajo el método de factores principales.

\section{Pautas de propagación, hospitalización y FALLECIMIENTO}

Al 31 de enero del 2021, el país registraba 1,9 millones de casos positivos acumulados, de los cuales, 496 mil 296 se correspondían con la CDMX (SISVER, 2021). Al interior de esta entidad, el 53,1\% del total de infecciones de Covid-19 se situaba en el rango etario de entre 25 y 50 años, complementándose con $15 ., 1 \%$ de casos con menos de 24 años y un $31,8 \%$ entre personas mayores de 50 años.

En términos de género, y exceptuando al subconjunto de nonagenarios, los subgrupos quinquenales de edad no muestran diferencias significativas. En prácticamente todos los rangos las distribuciones de contagio tienden a dividirse entre un $50 \%$ de casos masculinos y el restante de femeninos. 
GrÁFiCO 1. Distribución DE CASOS POSITIVOS DE COVID-19 RECONOCIDOS POR LA AUTORIDAD SANITARIA AL 31 DE ENERO DEL 2021, SEGÚN GRUPO DE EDAD Y SEXO

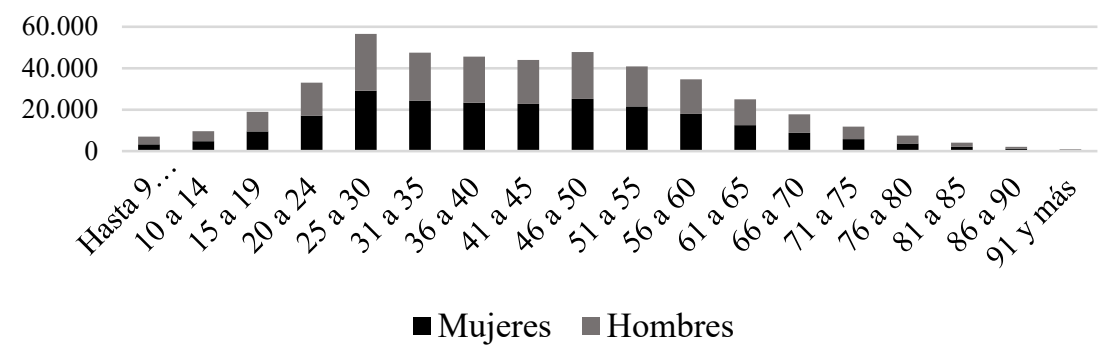

Fuente: Elaboración propia con base en SISVER, 2021.

En lo tocante a la dinámica y el flujo temporal de propagación, la trama nos permite ratificar algunos de los patrones etarios previamente advertidos. Con base en el reporte de la fecha de inicio de síntomas, y expresándolo en el número de días transcurridos desde la detección del paciente cero, podemos notar dos cuestiones.

Por un lado, está la tendencia general del ciclo de contagio, el cual alrededor del día 280, coincidente con el mes de octubre del 2020, refleja un importante escalamiento en el número de infecciones. Este dato debe ser tratado con cautela, en tanto no solo representa un aumento real y significativo de la propagación del virus; también incorpora un efecto asociado a cambios sobre la estrategia de vigilancia epidemiológica. Con la adición de casos dictaminados sin prueba, a partir del 5 de octubre de 2020 y la inclusión de registros determinados mediante prueba de antígeno, desde el 27 de noviembre, se introdujo una importante variante metodológica. Asimismo, para el cierre del año, el gobierno capitalino apostó por la duplicación sustancial en el número disponible de pruebas.

Por otro lado, y sin desestimar un repunte real en la curva de contagio, se puede apreciar (gráfico 2) que, al margen del ritmo general de propagación, el 
flujo de casos positivos tiende a diferenciarse a la luz de los subgrupos etarios de pertenencia. Más allá de la evidente asimetría de proporciones, la velocidad de transmisión del virus propende a ser mayor entre los subconjuntos etarios comprendidos entre los 25 y los 50 años; sobresaliendo el subgrupo de jóvenes comprendidos entre 25 y 30 años. Este dato ha prevalecido ignorado tanto en las estrategias de comunicación ensayadas por las autoridades sanitarias, como en la cobertura que los medios de comunicación realizan sobre el particular; ignorándose el impacto significativo que este virus ha tenido en la población joven.

Aunque, en una primera instancia, la distinción anterior pudiese parecer obvia, vale la pena recordar que hasta la fecha no se cuenta con un perfil sociodemográfico certero sobre los factores que pudiesen coadyuvar a una mayor propensión de contracción de la Covid-19. En buena medida, y a diferencia de lo que acontece con el riesgo de mortalidad y de hospitalización, la probabilidad de infectarse con el virus SARS-CoV-2 no solo depende de las condiciones de salud de las personas. Los datos anteriores sugieren que gente relativamente joven y con circunstancias muy heterogéneas de lozanía y bienestar físico, pueden estar igualmente expuestas a padecer la enfermedad. 
GRÁFICO 2. DistribuCiÓN DE CASOS POSITIVOS DE COVID-19 RECONOCIDOS POR LA AUTORIDAD SANITARIA AL 31 DE ENERO DE 2021, SEGÚN GRUPO DE EDAD

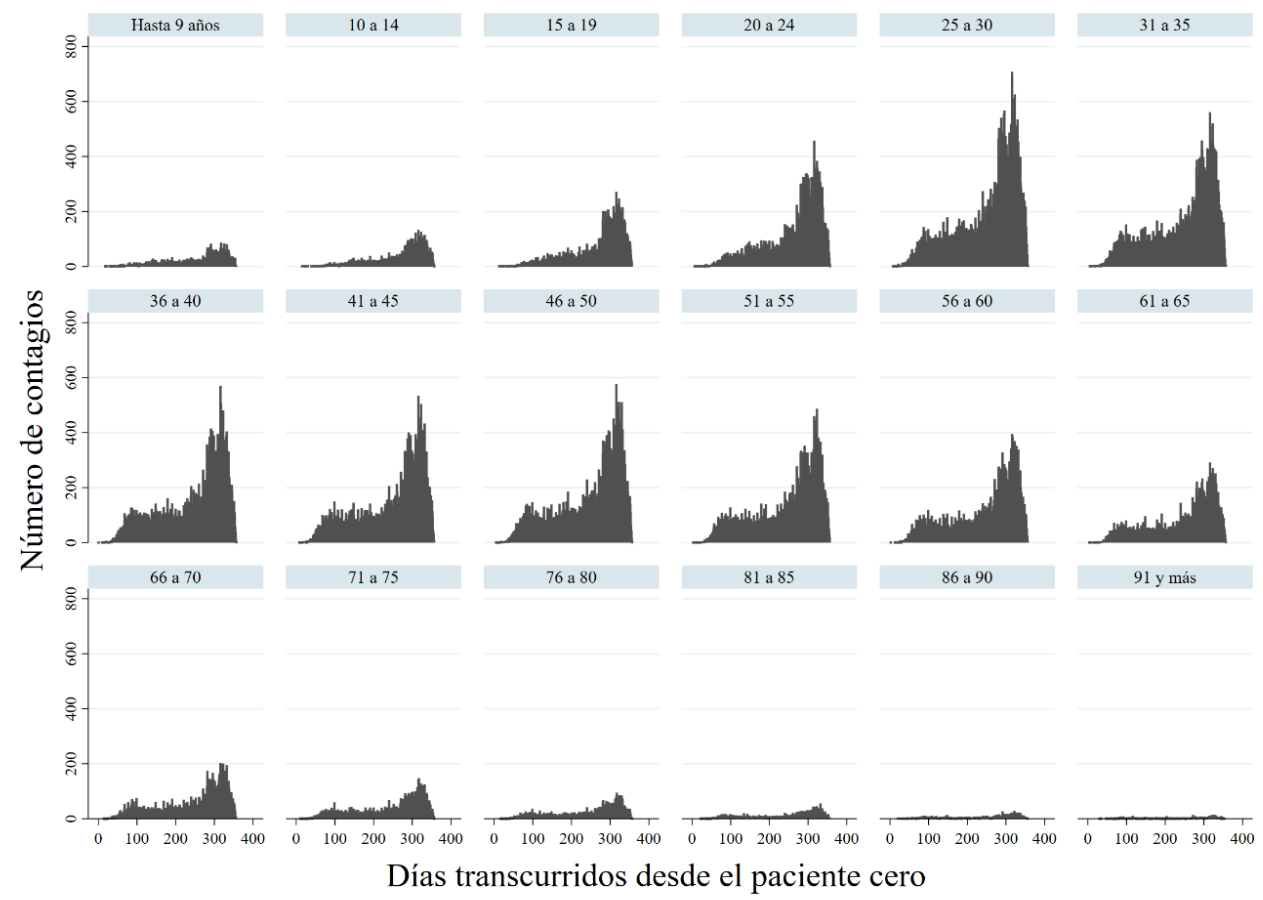

Fuente: Elaboración propia con base en SISVER, 2021.

De hecho, a partir de la información consignada en el registro del SISVER (2021), se conoce que seis de cada diez personas con positividad al virus SARSCoV-2, situadas entre los 20 y los 50 años, estuvieron en contacto con un caso de infección respiratoria viral en los siete días previos a la manifestación de síntomas. Este patrón difiere significativamente con otros rangos etarios, toda vez que entre los menores de 20 años hasta el 70\% de los casos reporta dicha condición, mientras que entre los mayores de 50 años solo se suscita en el 50\%.

A su vez, se puede establecer que, entre los subgrupos con positividad de 25 a 35 años, la prevalencia de comorbilidades y riesgos a la salud es relativamente baja; y las mismas se incrementan, notoriamente, conforme avanza 
la edad (cuadro 2). Cuestiones como el tabaquismo, la obesidad, la hipertensión y la diabetes presentan diferencias importantes asociadas al proceso de envejecimiento. Pese a ello, se trata de una dinámica de contagios donde el grueso de la distribución no parece obedecer a rasgos constitutivos de antecedencia clínica, sino a la configuración de circunstancias sociales propicias para la propagación del virus.

Cuadro 2. Porcentaje de casos positivos Covid-19 CON Alguna COMORBILIDAD O FACTOR DE RIESGO A LA SALUD, AL INTERIOR DE CADA SUBCONJUNTO ETARIO DE PERTENENCIA (\%)

\begin{tabular}{|c|c|c|c|c|c|c|c|c|c|}
\hline Edad & 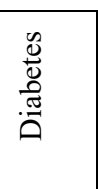 & 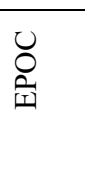 & 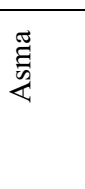 & 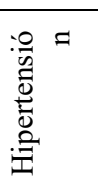 & $\stackrel{\Xi}{\nabla}$ & 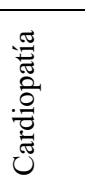 & $\begin{array}{l}\overrightarrow{\widetilde{J}} \\
\text { 岛 } \\
0 \\
0\end{array}$ & 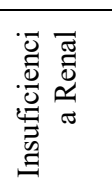 & 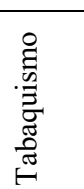 \\
\hline 25 a 30 & 1,23 & 0,08 & 2,43 & 1,82 & 0,37 & 0,38 & 9,51 & 0,33 & 13,31 \\
\hline 31 a 35 & 2,26 & 0,13 & 2,38 & 3,14 & 0,45 & 0,44 & 12,02 & 0,45 & 12,84 \\
\hline 36 a 40 & 4,3 & 0,21 & 2,08 & 5,34 & 0,38 & 0,55 & 13,88 & 0,52 & 12,55 \\
\hline 41 a 45 & 7,99 & 0,32 & 2,08 & 9,17 & 0,37 & 0,82 & 14,84 & 0,62 & 11,13 \\
\hline 46 a 50 & 11,81 & 0,48 & 1,85 & 13,89 & 0,36 & 1,06 & 15,14 & 0,84 & 9,63 \\
\hline
\end{tabular}

Fuente: Elaboración propia con base en SISVER, 2021

De esa manera, aspectos como la condición ocupacional adquieren una relevancia central, asumiendo que el modus vivendi de las personas engloba tanto sus alternativas de supervivencia económica como las circunstancias que median entre la calidad de su espacio domiciliar y sus pautas de interacción cotidiana. Sin datos que precisen con mayor exactitud el perfil de la gente infectada, el cuadro 3 muestra que, en la CDMX, prima una mayor propagación entre las clases trabajadoras. 
CUADRO 3. DisTRIBUCIÓN DE CASOS POSITIVOS, SEGÚN CATEGORÍA OCUPACIONAL Y GRUPOS DE EDAD (\%)

\begin{tabular}{|l|r|r|r|r|r|r|r|r|}
\hline & $\begin{array}{c}15 \mathrm{a} \\
19\end{array}$ & $\begin{array}{c}20 \\
24\end{array}$ & $\begin{array}{c}25 \mathrm{a} \\
\text { a }\end{array}$ & $\begin{array}{c}31 \mathrm{a} \\
\text { a }\end{array}$ & $\begin{array}{c}36 \\
40\end{array}$ & $\begin{array}{c}41 \mathrm{a} \\
45\end{array}$ & $\begin{array}{c}46 \mathrm{a} \\
50\end{array}$ & Total \\
\hline Empleados* & 10,8 & 34,8 & 43,3 & 44,2 & 44,4 & 42,9 & 42,0 & 40,3 \\
\hline Otros** & 6,1 & 13,3 & 20,5 & 22,2 & 21,5 & 20,3 & 19,0 & 18,9 \\
\hline Hogar & 3,4 & 7,8 & 10,1 & 11,5 & 12,6 & 14,6 & 17,0 & 11,8 \\
\hline Estudiantes & 76,1 & 33,5 & 7,6 & 1,5 & 0,6 & 0,4 & 0,3 & 10,6 \\
\hline $\begin{array}{l}\text { Empleados de la } \\
\text { salud*** }\end{array}$ & 0,4 & 2,4 & 7,7 & 7,9 & 6,6 & 5,3 & 4,2 & 5,5 \\
\hline $\begin{array}{l}\text { Comerciantes (fijos o } \\
\text { ambulantes) }\end{array}$ & 0,9 & 3,0 & 4,0 & 4,7 & 5,2 & 6,0 & 6,4 & 4,7 \\
\hline Desempleados & 1,7 & 3,0 & 3,0 & 2,7 & 2,8 & 3,0 & 3,0 & 2,8 \\
\hline Choferes & 0,1 & 0,7 & 1,4 & 2,1 & 2,8 & 3,5 & 3,9 & 2,3 \\
\hline Obreros & 0,3 & 1,1 & 1,2 & 1,4 & 1,6 & 1,9 & 2,0 & 1,5 \\
\hline Docentes & 0,0 & 0,3 & 0,9 & 1,3 & 1,4 & 1,4 & 1,3 & 1,1 \\
\hline Propietarios de negocios & 0,0 & 0,1 & 0,2 & 0,3 & 0,3 & 0,3 & 0,3 & 0,2 \\
\hline Jubilado/Pensionado & 0,0 & 0,1 & 0,1 & 0,1 & 0,1 & 0,2 & 0,6 & 0,2 \\
\hline Campesinos & 0,0 & 0,1 & 0,1 & 0,1 & 0,1 & 0,2 & 0,2 & 0,1 \\
\hline Total & 100,0 & 100,0 & 100,0 & 100,0 & 100,0 & 100,0 & 100,0 & 100,0 \\
\hline
\end{tabular}

* Categoría general que recoge a empleados asalariados, según el propio diccionario de datos del SISVER.

** No se especifica con precisión el campo laboral.

*** En esta categoría se engloba al personal médico, hospitalario, dentistas y laboratoristas.

Fuente: Elaboración propia con base en SISVER, 2021.

La dinámica de contagio sugiere que el riesgo de exposición de los contingentes juveniles es de similar magnitud al de los grupos poblacionales en edades de entre 36 y 50 años. Sobre este particular, la evidencia empírica no permite sostener la tesis según la cual la población joven es menos propensa que la adulta en cuanto al contagio de la Covid-19. Las diferencias sustantivas se expresan en dos vetas complementarias de análisis referentes a la evolución de la enfermedad y la distribución de decesos.

Entre los grupos etarios menores a 35 años, el porcentaje de personas hospitalizadas es menor al 5\%; mientras que entre los mayores de 35 y menores de 50, la proporción ronda entre el 5\% y el 10\%. Únicamente a partir de los 60 
años, dicho volumen propende a superar el 20\%, alcanzando proporciones superiores al 30\% a partir de los 66 años (SISVER, 2021).

GRÁFICO 3. DisTRIBUCIÓN DE CASOS POSITIVOS DE COVID-19 RECONOCIDOS POR LA AUTORIDAD SANITARIA AL 31 DE ENERO DEL 2021, SEGÚN GRUPO DE EDAD Y TIPO DE PACIENTE

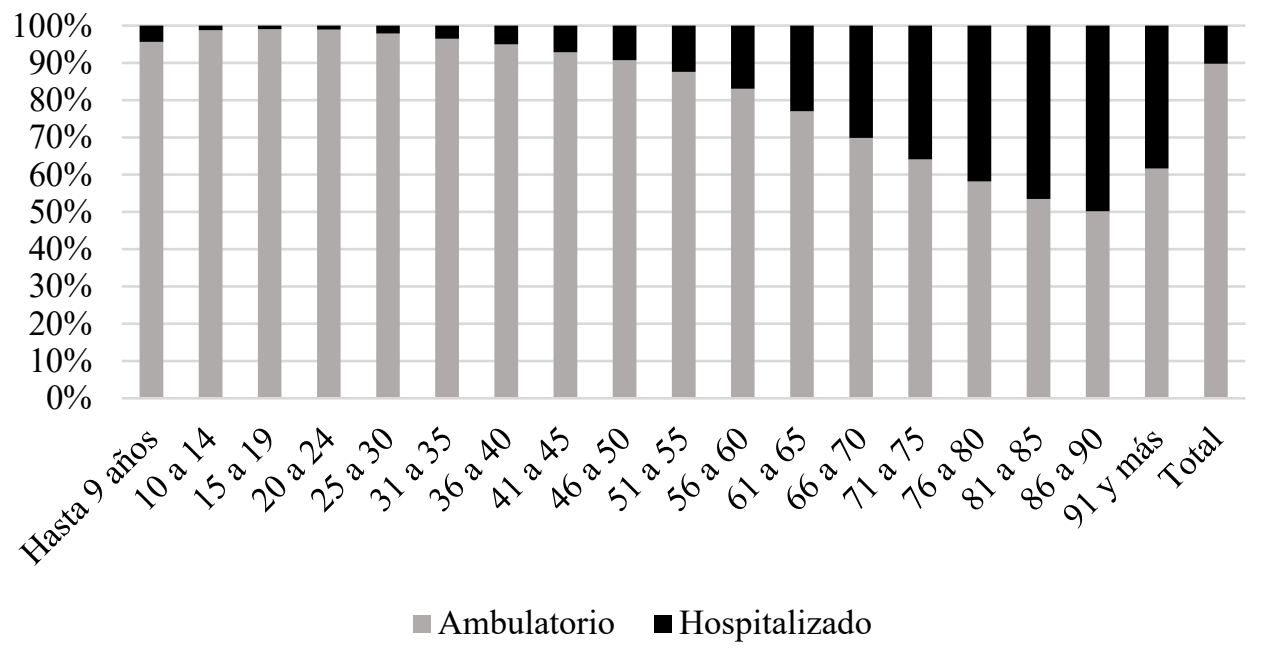

Fuente: Elaboración propia con base en SISVER, 2021.

En la distribución general, el 64\% de los casos con positividad al virus SARS-CoV-2 no posee comorbilidad alguna; el 33\% posee hasta dos patologías o factores de riesgo a la salud; mientras que en el 3\% se conjugan más de dos antecedentes clínicos de vulnerabilidad (SISVER, 2021). Centrando la mirada solo en el $10 \%$ de personas que requirieron hospitalización, podemos confirmar que la presencia de enfermedades o agravantes previos sigue un patrón progresivo al interior de los distintos grupos de edad. A diferencia del flujo de contagio, la pauta de hospitalización está afectada por los antecedentes médicos, siendo estos últimos mucho más benevolentes entre la población juvenil. 
GRÁFICO 4. DISTRIBUCIÓN DE CASOS POSITIVOS DE COVID-19 QUE REQUIRIERON HOSPITALIZACIÓN, SEGÚN GRUPO DE EDAD Y ANTECEDENTES CLÍNICOS DE RIESGO

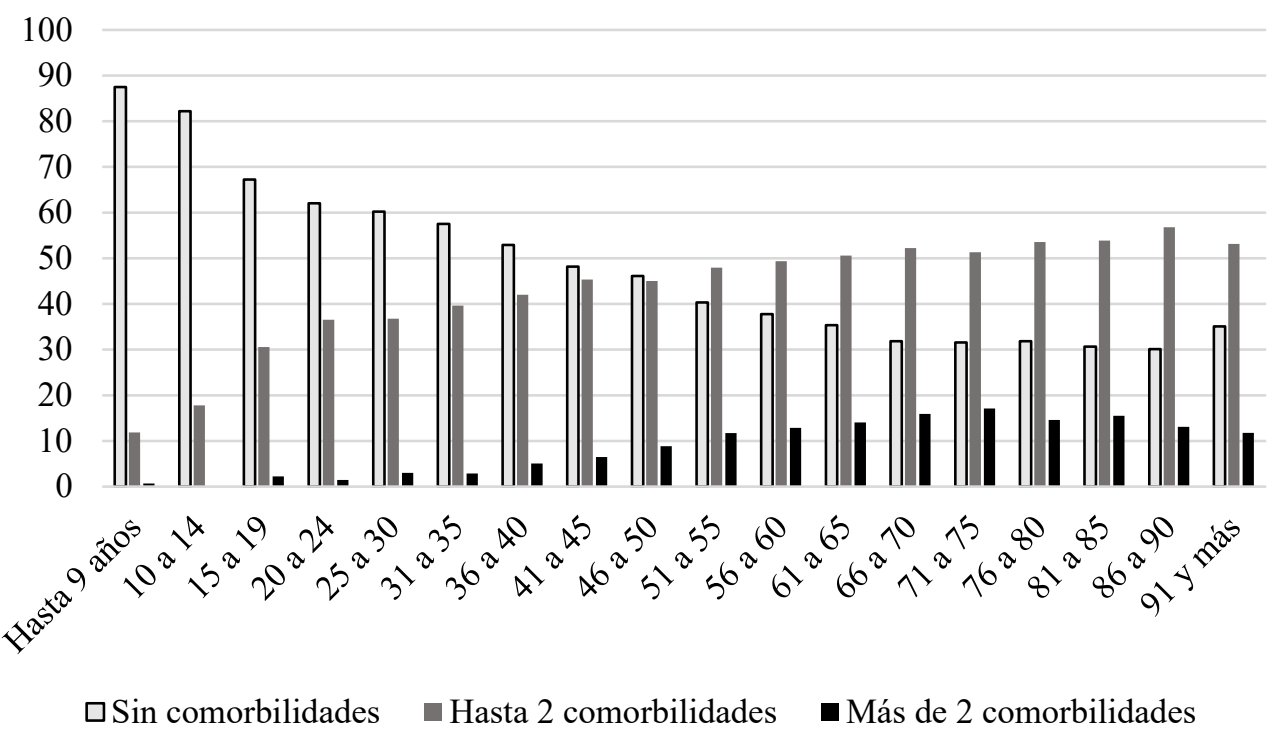

Fuente: Elaboración propia con base en SISVER, 2021.

Este patrón permite sostener que, aunque los jóvenes se contagian de la Covid-19 en mayor propensión que los adultos mayores, tienen menores probabilidades de que su enfermedad derive en complicaciones severas de salud. En el discurso público suele sostenerse que, al tener conciencia de este patrón, las poblaciones juveniles tienden a asumir conductas más laxas frente a las medidas de distanciamiento social y autocuidado de la salud. Empero, hasta la fecha, esta apreciación no se sustenta en evidencia empírica rigurosa, cuestión que someteremos a prueba más adelante.

Así pues, los datos sobre decesos nos permiten observar la otra cara de esta enfermedad. Al 31 de enero de 2021, la capital acumulaba 41.037 actas de defunción en el Registro Civil con causa de muerte o sospecha por Covid-19 entre residentes de la CDMX (SEDESA, 2021a). De ese total, 19.342 fueron 
clasificados por presunción de positividad al virus SARS-CoV-2, mientras que 21.695 casos eran confirmados. Proporcionalmente, estos últimos equivalían al $14,5 \%$ de fallecimientos a nivel nacional. Con corte al 16 de enero de ese mismo año, el gobierno capitalino estimaba una tasa de letalidad del 5,1\%.

Según el subgrupo etario de pertenencia, el 1,4\% de defunciones por padecimiento o sospecha de Covid-19 se situaban en el rango de 0 a 30 años; $15,8 \%$ se ubicaba entre 31 y 50 años; 49,2\% entre 51 y 70 años; y un restante 33,6\% se correspondía con personas de entre 71 y más (SEDESA, 2021b).

En abierto contraste con la lógica de contagio, la letalidad está concentrada en los sectores poblacionales de mayor edad. Asimismo, a diferencia de la trayectoria de propagación, la curva evolutiva de decesos refleja la conformación de dos picos, uno acontecido en junio de 2020 y otro suscitado en enero de 2021. De acuerdo con el reporte emitido a partir del Registro Civil (SEDESA, 2021a), hasta el 40,7\% de los casos hospitalizados perecieron por complicación. 
GRÁFICO 5. DISTRIBUCIÓN DE DECESOS ENTRE CASOS CONFIRMADOS O CON SOSPECHA DE COVID-19 EN LA CDMX AL 31 DE ENERO DE 2021, SEGÚN GRUPO DE EDAD

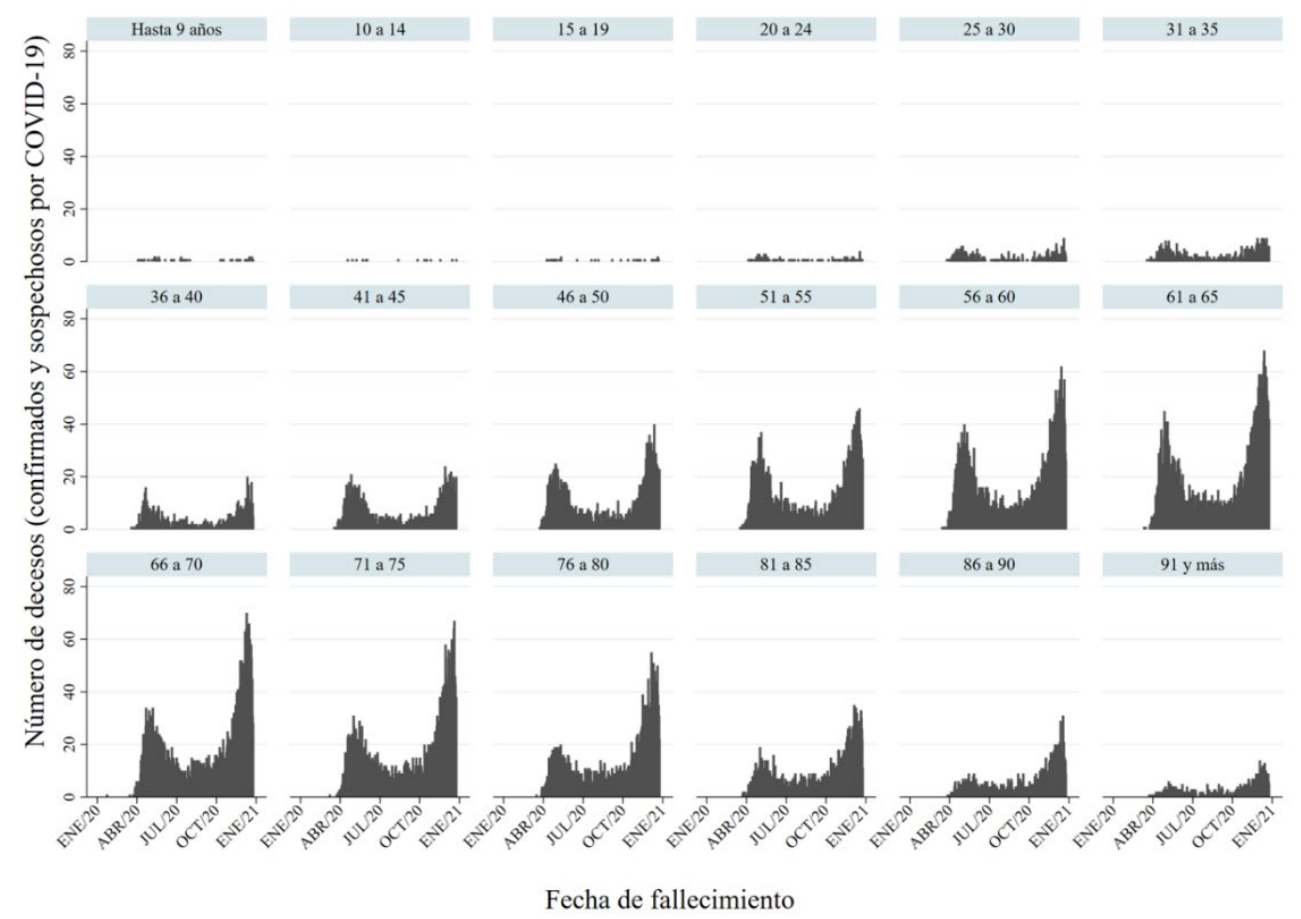

Fuente: Elaboración propia con base en SEDESA, 2021 b.

Al interior del subconjunto de 21.695 fallecimientos confirmados por Covid-19, y pese a que el número de decesos es mucho menor entre las poblaciones menores a 50 años, es interesante notar la relación entre la presencia de antecedentes clínicos adversos y la pauta de mortalidad. Del total de muertes oficialmente confirmadas en la CDMX, a inicios de 2021, hasta un 65,7\% de las personas presentaba alguna comorbilidad (SISVER, 2021). En el subgrupo de menos de 35 años, solo cinco de cada diez pacientes contaban con algún precedente médico de riesgo, mientras que en el conglomerado de 36 y más años, dicha situación se suscitaba en siete de cada diez. Aunque las circunstancias 
médicas agravantes y la fatalidad tienden a ser más agudas entre la gente de mayor edad, llama la atención que entre las/os jóvenes se produzcan muertes hasta en un $50 \%$ de casos exentos de alguna comorbilidad. Esto, de nueva cuenta, muestra una faceta poco tematizada por las autoridades sanitarias e ignorada en la estrategia de información de los medios de comunicación, contribuyendo, por esta vía, a minimizar el riesgo que para la población joven conlleva contraer este virus.

\section{GRÁFICO 6. DISTRIBUCIÓN DE COMORBILIDADES ENTRE FALLECIMIENTOS}

CONFIRMADOS POR COVID-19 EN LA CDMX, SEGÚN GRUPO ETARIO (\%)

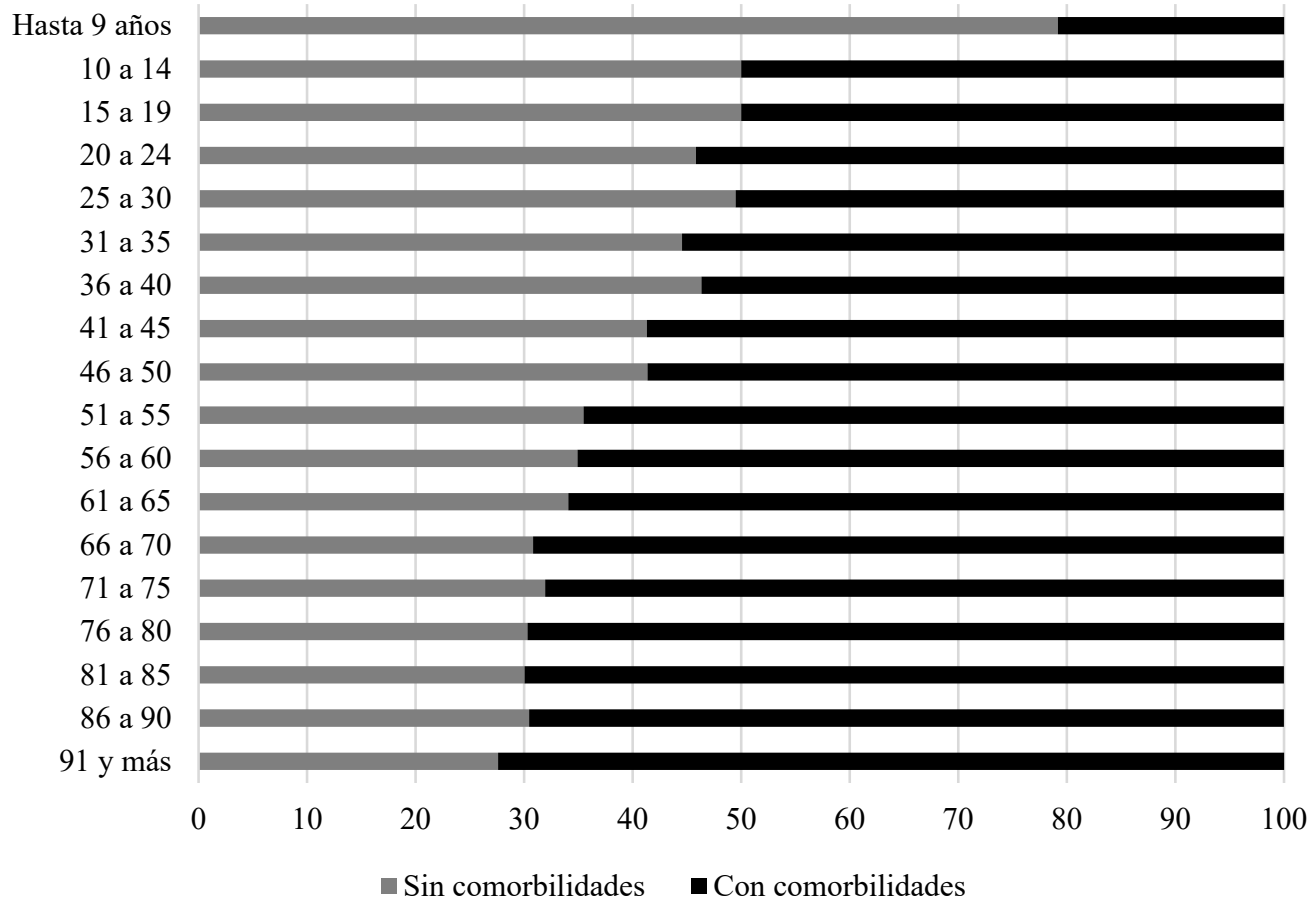

Fuente: Elaboración propia con base en SISVER, 2021.

Hasta este punto, el análisis del flujo de la pandemia nos permite establecer una distinción básica en torno a la población juvenil. Tal como reflejan 
los datos previamente discutidos, las dinámicas de contagio, de hospitalización y de mortalidad se comportan de manera relativamente diferenciada según se trate de personas jóvenes o adultas. Por un lado, está la lógica de propagación en la cual los contingentes juveniles reportan pautas similares a los de otros grupos etarios predominantes de la población trabajadora. Por otro, está el patrón de internamiento hospitalario y de fallecimiento, donde priman los sectores de mayor edad y con mayor propensión a la tenencia de antecedentes de riesgo clínico.

En virtud de lo anterior, se puede establecer que las juventudes cumplen con un papel no desdeñable en la prosecución de cadenas de contagio. Empero, esta es una característica que comparten con la población adulta comprendida en el rango etario de 30 a 50 años. Pese a ello, en el discurso público la población joven aparece constantemente señalada como negligente en el acatamiento de las principales medidas de prevención y, en consecuencia, se les asigna una mayor responsabilidad en la propagación de la Covid-19. A manera de contrastar algunas de estas nociones, en el siguiente apartado se exploran ciertas prácticas e imaginarios imperantes entre jóvenes pertenecientes a sectores urbanopopulares de la CDMX

\section{DEL ESTIGMA A LA REALIDAD}

De cara a la irrupción de la pandemia, tanto en el discurso académico como en el acontecer político, las antípodas entre la displicencia y la corresponsabilidad personal han ocupado un lugar central (Van Rooij et al., 2020; Harper et al., 2020). Autoridades locales e internacionales coinciden al señalar que el aislamiento social, la portación de cubrebocas y los hábitos de higiene constituyen no solo un compromiso voluntario sino una responsabilidad cívica para mitigar la propagación del SARS-CoV-2 (ONU, 2020; OMS, 2020; Chertorivski et al., 2020; Gobierno de México, 2020a). 
No obstante, como ya señalábamos antes, la decisión de acatar o ignorar las recomendaciones preventivas no puede pasar por alto que no todas las personas cuentan con las mismas condiciones para garantizar su cumplimiento. Aspectos como las privaciones materiales, las asimetrías laborales, el autoempleo de subsistencia, la fatiga económica y la desconfianza institucional confrontan a los ciudadanos con el dilema de atender las medidas preventivas para disminuir el riesgo de contagio o reemprender las acciones que les permitan obtener recursos para el sustento de sus familias (Levy y Sartorio, 2020; Wright et al., 2020; Bargain y Aminjonov, 2020).

Como mostramos en el apartado anterior, los flujos de propagación, hospitalización y mortalidad se conducen de manera relativamente distintiva dependiendo del grupo etario observado. No obstante, las juventudes han figurado como un referente particular de la displicencia y la prosecución de contagios. Este señalamiento se ha producido en el entremedio de profundas contradicciones.

Por un lado, se ha enfatizado que de cada diez casos infecciosos siete son asintomáticos, uno presenta síntomas leves y solo dos pueden derivar en una eventual complicación (INSP, 2020). En esa pauta comunicada a la población general, las personas jóvenes aparecen como el subgrupo con menores riesgos frente a un eventual contagio de la Covid-19; lo cual, como hemos analizado, no es del todo correcto, al menos en lo que al contagio se refiere.

Asimismo, pese a que el gobierno federal ha sostenido una estrategia de difusión encabezada por el titular de la Subsecretaría de Prevención y Promoción de la Salud, los mensajes emitidos no han estado exentos de contradicciones. Así ha acontecido con asuntos particulares, tales como el uso del cubrebocas o el llamado voluntario al distanciamiento social y al confinamiento domiciliar. De estos, pueden recordarse las declaraciones emitidas el 27 de abril del 2020, cuando el Dr. Hugo López-Gatell, responsable principal de la estrategia de 
prevención y combate al Covid-19, afirmó que la portación de mascarillas «tiene una pobre [...] o nula utilidad», tan solo para reconocer, un mes después, que dicha medida es un auxiliar importante en la disminución de riesgos de propagación (Chávez, 2020). De entre las acuciantes polémicas, destaca la contraposición entre el llamado permanente a quedarse en casa y la conducta de las principales autoridades. Así sucedió con el presidente López Obrador, quien desde el 29 de mayo anunció que, aunque el país se encontraba en semáforo rojo, reiniciaría sus giras por los diversos estados del país (Ferrer, 2020), o con el propio López-Gatell, que en diciembre de 2020, y en pleno repunte de casos, fue captado vacacionando en el Pacífico mexicano. Ambas figuras fueron reportadas como infectadas de Covid-19 en los primeros meses del 2021.

En el entremedio de los llamados a la corresponsabilidad y los visos de incongruencia por parte de la autoridad, no sorprende que entre la muestra de encuestados/as prevalezcan percepciones de riesgo claramente disímiles.

Por difusión informativa, por la naturaleza de las cifras diarias reportadas en torno a la Covid-19 o por atención a los mensajes reiterados de la autoridad gubernamental, las/os jóvenes reportan menor agobio por los asuntos directamente relacionados con la salud en contraste con la población adulta (cuadro 4). Conscientes de que el contagio puede derivar en enfermedad asintomática, menor propensión a la hospitalización y a la fatalidad, las tribulaciones de las juventudes encuestadas se centran en los efectos económicos, emocionales y afectivos de la crisis sanitaria. Aunque este último rasgo es transversal a la muestra general, llama la atención que los peligros médicos de la pandemia tiendan a reflejarse tan fielmente en la progresión por grupos de edad. 
CuAdRo 4. Percepción DE RIESGOS ASOCIADO A LA COVID-19, SEGÚN GRUPO DE $\operatorname{EDAD}(\%)$

\begin{tabular}{|c|c|c|c|c|c|}
\hline \multicolumn{2}{|c|}{ Percepción de riesgo } & Hasta 35 & $36-55$ & 56 y más & Total \\
\hline \multirow{3}{*}{ Contagio } & Muy Bajo/Bajo & 50,8 & 37,7 & 37,3 & 42,1 \\
\hline & Alto/Muy Alto & 49,2 & 62,3 & 62,8 & 57,9 \\
\hline & \multicolumn{5}{|c|}{ Pearson chi2 $(2)=5,8675 \operatorname{Pr}=0,053$} \\
\hline \multirow{3}{*}{ Hospitalización } & Muy Bajo/Bajo & 77,4 & 48,7 & 23,5 & 54,9 \\
\hline & Alto/Muy Alto & 22,6 & 51,3 & 76,5 & 45,1 \\
\hline & \multicolumn{5}{|c|}{ Pearson $\operatorname{chi} 2(2)=48,6450 \mathrm{Pr}=0,000$} \\
\hline \multirow{3}{*}{$\begin{array}{l}\text { Pasar mayores } \\
\text { privaciones }\end{array}$} & Muy Bajo/Bajo & 21,8 & 3,7 & 2,0 & 9,6 \\
\hline & Alto/Muy Alto & 78,2 & 96,3 & 98,0 & 90,4 \\
\hline & \multicolumn{5}{|c|}{ Pearson chi2 $(2)=32,4708 \mathrm{Pr}=0,000$} \\
\hline \multirow{3}{*}{$\begin{array}{l}\text { Pérdida de empleo o } \\
\text { fuentes de ingreso }\end{array}$} & Muy Bajo/Bajo & 35,5 & 13,1 & 51,0 & 26,0 \\
\hline & Alto/Muy Alto & 64,5 & 86,9 & 49,0 & 74,0 \\
\hline & \multicolumn{5}{|c|}{ Pearson $\operatorname{chi} 2(2)=38,9281 \mathrm{Pr}=0,000$} \\
\hline \multirow{3}{*}{ Morir por Covid-19 } & Muy Bajo/Bajo & 91,1 & 59,2 & 15,7 & 63,9 \\
\hline & Alto/Muy Alto & 8,9 & 40,8 & 84,3 & 36,1 \\
\hline & \multicolumn{5}{|c|}{ Pearson chi2 $(2)=93,1445 \mathrm{Pr}=0,000$} \\
\hline \multirow{3}{*}{$\begin{array}{l}\text { Complicaciones } \\
\text { emocionales o } \\
\text { psicológicas }\end{array}$} & Muy Bajo/Bajo & 34,7 & 34,0 & 58,8 & 37,7 \\
\hline & Alto/Muy Alto & 65,3 & 66,0 & 41,2 & 62,3 \\
\hline & \multicolumn{5}{|c|}{ Pearson $\operatorname{chi} 2(2)=11,2651 \mathrm{Pr}=0,004$} \\
\hline \multirow{3}{*}{$\begin{array}{c}\text { Perjuicio a sus } \\
\text { relaciones familiares } \\
\text { o afectivas }\end{array}$} & Muy Bajo/Bajo & 36,3 & 31,4 & 17,7 & 31,2 \\
\hline & Alto/Muy Alto & 63,7 & 68,6 & 82,4 & 68,9 \\
\hline & \multicolumn{5}{|c|}{ Pearson chi2 $(2)=5,8699 \operatorname{Pr}=0,053$} \\
\hline
\end{tabular}

Fuente: Elaboración propia.

Ante tal distinción en la percepción de incertezas en torno a la pandemia, cabe preguntarse si efectivamente las personas más jóvenes exhiben comportamientos más displicentes en comparación con la población adulta.

Como se aprecia en el cuadro 5, de las ocho recomendaciones básicas para mitigar las cadenas y riesgos de contagio, promovidas por las autoridades de salud, solo una presenta contrastes sustantivos entre las/os jóvenes menores de 35 años, las/os adultas/os de 36 a 55 y las personas de 56 y más edad.

En consonancia con otras encuestas (Mitofsky, 2020; UIA, 2020), nuestros indicios apuntan a que la vasta mayoría de la gente atiende los llamados al uso de mascarillas, al lavado frecuente de manos, a evitar reuniones o espacios concurridos y a respetar la distancia social. Asimismo, coincide que la población 
joven no se diferencia en el ejercicio de estas prácticas de prevención respecto de la pauta observada entre los adultos.

De entre el repertorio de medidas cautelares, el confinamiento doméstico aparece como la única medida frente a la cual las juventudes ostentan mayores resistencias o dificultades para su cumplimiento. Esto último suele interpretarse generalmente como una conducta particular, derivada de la centralidad otorgada a los espacios de sociabilidad durante la fase de vida juvenil. La pregunta es si, en efecto, esto es lo que motiva su reticencia a mantener el confinamiento residencial o si existen otras razones de mayor peso detrás de esta conducta.

CUAdRO 5. FRECUENCIA CON QUE SE PRACTICAN LAS PRINCIPALES RECOMENDACIONES DE PREVENCIÓN DE CONTAGIO, SEGÚN GRUPO ETARIO DE PERTENENCIA $(\%)$

\begin{tabular}{|c|c|c|c|c|c|}
\hline $\begin{array}{l}\text { Medida de } \\
\text { nrevención }\end{array}$ & Frecuencia & Hasta 35 & 36-55 & 56 y más & Total \\
\hline \multirow{4}{*}{$\begin{array}{l}\text { Portación de } \\
\text { cubrebocas en } \\
\text { espacios públicos }\end{array}$} & $\begin{array}{l}\text { Nunca/Algunas } \\
\text { veces }\end{array}$ & 27,4 & 22,5 & 25,5 & 24,6 \\
\hline & $\begin{array}{l}\text { La mayor parte del } \\
\text { tiempo }\end{array}$ & 53,2 & 48,7 & 43,1 & 49,5 \\
\hline & Todo el tiempo & 19,4 & 28,8 & 31,4 & 26,0 \\
\hline & \multicolumn{5}{|c|}{ Pearson chi2 $(4)=4,7978 \operatorname{Pr}=0,309$} \\
\hline \multirow{4}{*}{$\begin{array}{l}\text { Lavado frecuente } \\
\text { de manos }\end{array}$} & $\begin{array}{l}\text { Nunca/Algunas } \\
\text { veces }\end{array}$ & 33,9 & 31,4 & 29,4 & 32,0 \\
\hline & $\begin{array}{l}\text { La mayor parte del } \\
\text { tiempo }\end{array}$ & 46,0 & 45,6 & 39,2 & 44,8 \\
\hline & Todo el tiempo & 20,2 & 23,0 & 31,4 & 23,2 \\
\hline & \multicolumn{5}{|c|}{ Pearson $\operatorname{chi} 2(4)=2,6415 \operatorname{Pr}=0,619$} \\
\hline \multirow{4}{*}{$\begin{array}{l}\text { Evita reuniones o } \\
\text { espacios } \\
\text { concurridos }\end{array}$} & $\begin{array}{l}\text { Nunca/Algunas } \\
\text { veces }\end{array}$ & 40,3 & 34,0 & 29,4 & 35,5 \\
\hline & $\begin{array}{l}\text { La mayor parte del } \\
\text { tiempo }\end{array}$ & 41,9 & 44,0 & 39,2 & 42,6 \\
\hline & Todo el tiempo & 17,7 & 22,0 & 31,4 & 21,9 \\
\hline & \multicolumn{5}{|c|}{ Pearson $\operatorname{chi} 2(4)=4,7700 \operatorname{Pr}=0,312$} \\
\hline \multirow{4}{*}{ Evita salir de casa } & $\begin{array}{l}\text { Nunca/Algunas } \\
\text { veces }\end{array}$ & 43,6 & 38,7 & 35,3 & 39,9 \\
\hline & $\begin{array}{l}\text { La mayor parte del } \\
\text { tiempo }\end{array}$ & 46,8 & 53,9 & 37,3 & 49,2 \\
\hline & Todo el tiempo & 9,7 & 7,3 & 27,5 & 10,9 \\
\hline & \multicolumn{5}{|c|}{ Pearson chi2 $(4)=18,4247 \operatorname{Pr}=0,001$} \\
\hline $\begin{array}{c}\text { Practica el } \\
\text { distanciamiento }\end{array}$ & $\begin{array}{l}\text { Nunca/Algunas } \\
\text { veces }\end{array}$ & 43,6 & 43,5 & 33,3 & 42,1 \\
\hline
\end{tabular}



apremios y prácticas de prevención

\begin{tabular}{|c|c|c|c|c|c|}
\hline $\begin{array}{l}\text { Medida de } \\
\text { prevención }\end{array}$ & Frecuencia & Hasta 35 & 36-55 & 56 y más & Total \\
\hline \multirow[t]{3}{*}{$\begin{array}{c}\text { social al salir de } \\
\text { casa }\end{array}$} & $\begin{array}{l}\text { La mayor parte del } \\
\text { tiempo }\end{array}$ & 46,0 & 43,5 & 41,2 & 44,0 \\
\hline & Todo el tiempo & 10,5 & 13,1 & 25,5 & 13,9 \\
\hline & \multicolumn{5}{|c|}{ Pearson $\operatorname{chi} 2(4)=7,3361 \operatorname{Pr}=0,119$} \\
\hline \multirow{4}{*}{$\begin{array}{c}\text { Evita recibir } \\
\text { visitas en el hogar }\end{array}$} & $\begin{array}{l}\text { Nunca/Algunas } \\
\text { veces }\end{array}$ & 36,3 & 31,4 & 17,7 & 31,2 \\
\hline & $\begin{array}{l}\text { La mayor parte del } \\
\text { tiempo }\end{array}$ & 33,1 & 36,7 & 37,3 & 35,5 \\
\hline & Todo el tiempo & 30,7 & 31,9 & 45,1 & 33,3 \\
\hline & \multicolumn{5}{|c|}{ Pearson $\operatorname{chi} 2(4)=6,8620 \operatorname{Pr}=0,143$} \\
\hline \multirow{4}{*}{$\begin{array}{l}\text { Evita hacer uso } \\
\text { del transporte } \\
\text { público }\end{array}$} & $\begin{array}{l}\text { Nunca/Algunas } \\
\text { veces }\end{array}$ & 32,3 & 27,8 & 31,4 & 29,8 \\
\hline & $\begin{array}{l}\text { La mayor parte del } \\
\text { tiempo }\end{array}$ & 34,7 & 37,7 & 25,5 & 35,0 \\
\hline & Todo el tiempo & 33,1 & 34,6 & 43,1 & 35,3 \\
\hline & \multicolumn{5}{|c|}{ Pearson chi2 $(4)=3,3776 \operatorname{Pr}=0,497$} \\
\hline \multirow{4}{*}{$\begin{array}{c}\text { Desinfecta víveres } \\
\text { y superficies }\end{array}$} & $\begin{array}{l}\text { Nunca/Algunas } \\
\text { veces }\end{array}$ & 23,4 & 17,8 & 23,5 & 20,5 \\
\hline & $\begin{array}{l}\text { La mayor parte del } \\
\text { tiempo }\end{array}$ & 41,9 & 43,5 & 37,3 & 42,1 \\
\hline & Todo el tiempo & 34,7 & 38,7 & 39,2 & 37,4 \\
\hline & \multicolumn{5}{|c|}{ Pearson $\operatorname{chi} 2(4)=2,1629 \mathrm{Pr}=0,706$} \\
\hline
\end{tabular}

Fuente: Elaboración propia.

En tónica semejante a la pauta de propagación discutida en el apartado anterior, la comparación entre jóvenes y adultos exhibe una distribución de contagio muy similar (cuadro 6). Del total de personas que declararon haber padecido la Covid-19 (32\%), y sin distinciones por grupo etario de pertenencia, el 60\% acudió a practicarse una prueba diagnóstica; mientras que el 40\% solo contó con una valoración médica. En contraste, entre las/os informantes sin contagio (68\%), cerca de una cuarta parte sospecha haber presentado alguno o varios de los síntomas de enfermedad. Sin diferencias significativas entre los subgrupos de edad, únicamente dos de cada diez se practicaron la prueba correspondiente. 
CUADRO 6. Distribución DE INFORMANTES QUE DECLARARON HABER PADECIDO COVID-19, SEGÚN GRUPOS DE EDAD (\%)

\begin{tabular}{|l|r|r|r|r|}
\hline & Hasta 35 & \multicolumn{1}{|c|}{$\mathbf{3 6 - 5 5}$} & 56 y más & \multicolumn{2}{c|}{ Total } \\
\hline Sin contagio & 65,3 & 65,5 & 84,3 & 68,0 \\
\hline Con contagio & 34,7 & 34,5 & 15,7 & 32,0 \\
\hline Total & 100 & 100 & 100 & 100 \\
\hline
\end{tabular}

Pearson chi2 $(2)=7.2228 \mathrm{Pr}=0.027$

Fuente: Elaboración propia.

Como se aprecia en el gráfico 7 , ni la condición de contagio ni la distinción etaria reflejan diferencias significativas en la prosecución de las recomendaciones de prevención. Por el contrario, los únicos indicios de aparente relevancia están dados por el tipo de ocupación. Y es que de acuerdo con la información proporcionada por las/os residentes entrevistadas/os, dichas actividades guardan una relación preponderante con el promedio de horas que día a día deben pasar fuera del hogar. 
GRÁFICO 7. PUNTAJE PROMEDIO DEL ÍNDICE SOBRE LA FRECUENCIA DE ACCIONES PREVENTIVAS FRENTE A LA COVID-19, SEGÚN CONDICIÓN DE CONTAGIO, OCUPACIÓN Y GRUPO ETARIO*

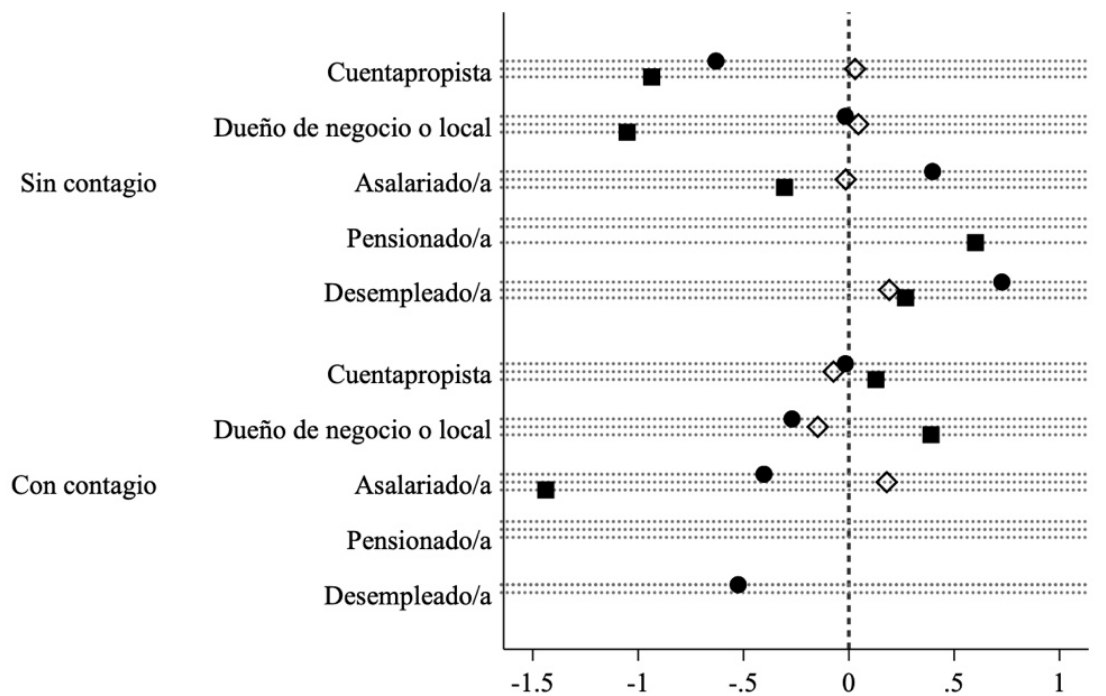

Índice factorial sobre la frecuencia de acciones preventivas frente a la COVID-19

- Hasta 35 años $\diamond 36$ a 55 @ 56 y más

* Índice obtenido por factores principales con retención del 96,4\% de la varianza y KMO de 0,8985. La medida sintética se expresa en unidades estandarizadas (media $=0$; desviación estándar $=1$ ). Asociación significativa solo para el tipo de ocupación (Prob $>\mathrm{F}=0,035$ ) y el puntaje promedio del índice factorial mediante ANOVA (Prob $>\mathrm{F}=0,0034)$. Ni los grupos de edad $($ Prob $>F=0,238)$ ni la condición de contagio $(\operatorname{Prob}>\mathrm{F}=0,97)$ exhiben diferencias significativas.

Fuente: Elaboración propia.

Hasta el $82 \%$ de las/os cuentapropistas sostienen jornadas cotidianas de más de seis horas lejos de casa. Así acontece también con el 79,4\% de las/os dueñas/os de negocios propios y con el 46,7\% de las/os trabajadoras/es 
asalariadas/os. En aras de comprender la importancia de este último dato, vale la pena señalar que ocho de cada diez personas que refirieron haberse infectado de SARS-CoV-2 se ubican en el grupo cuyas responsabilidades económicas les demandan más de seis horas diarias ausentes de su domicilio.

Con condiciones laborales altamente diversas, el tiempo destinado para generar ingresos juega un papel clave en la capacidad para llevar a cabo las principales medidas de prevención, en particular el llamado a «quedarse en casa». Tal cual se recoge en el gráfico 8 , aquellos/as con jornadas más largas de trabajo presentan puntajes del índice sobre la frecuencia de acciones preventivas por debajo del promedio. Esto implica que, en contraste con quienes cuentan con esquemas de manutención más flexibles, entre los subgrupos de trabajadores/as con mayores apremios económicos, persisten mayores dificultades para sostener cautelas directamente relacionadas tanto con el distanciamiento social como con el confinamiento residencial.

GRÁFICO 8. PUNTAJE PROMEDIO DEL ÍNDICE SOBRE LA FRECUENCIA DE ACCIONES PREVENTIVAS FRENTE A LA COVID-19, SEGÚN GRUPO ETARIO, TIPO DE OCUPACIÓN Y TIEMPO PROMEDIO DE HORAS FUERA DE CASA* 


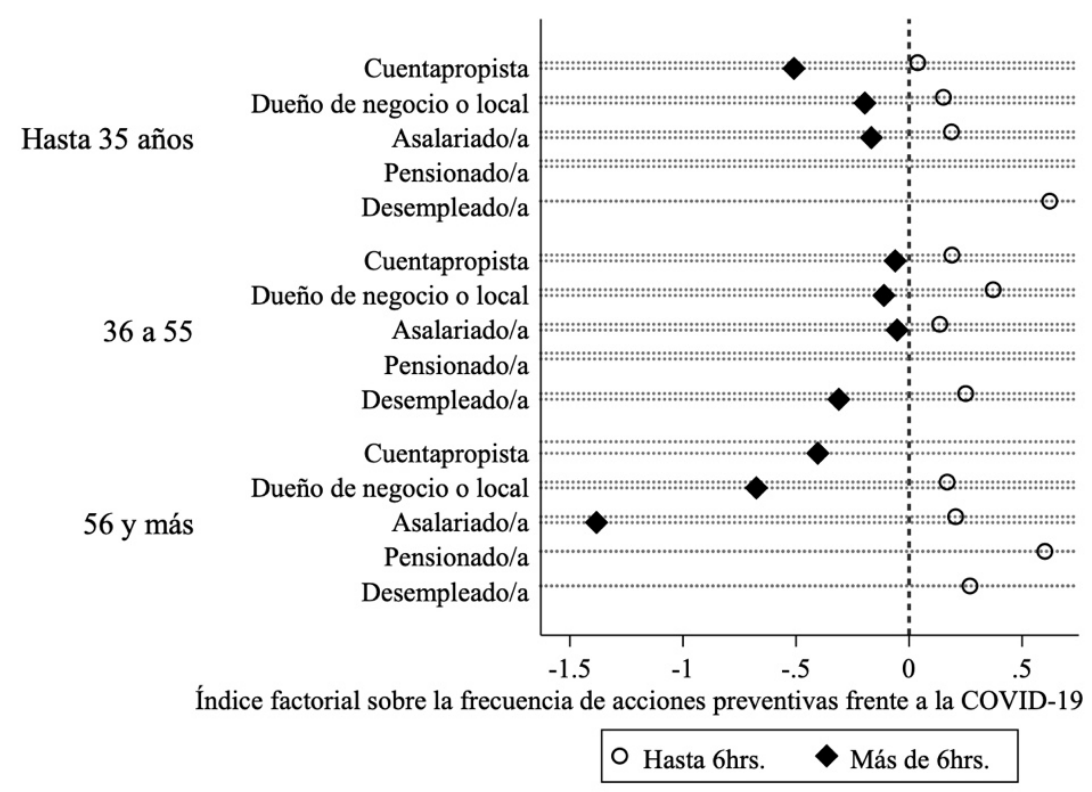

* Índice obtenido por factores principales con retención del 96,4\% de la varianza y KMO de 0,8985. La medida sintética se expresa en unidades estandarizadas (media $=0$; desviación estándar=1). Asociación significativa solo para el tipo de ocupación (Prob $>\mathrm{F}=0,035$ ) y el puntaje promedio del índice factorial mediante ANOVA (Prob $>\mathrm{F}=0,0034)$. Ni los grupos de edad $(\operatorname{Prob}>\mathrm{F}=0 ., 38)$ ni la condición de contagio $(\mathrm{Prob}>\mathrm{F}=0,97)$ exhiben diferencias significativas.

Fuente: Elaboración propia.

Entre aquellos/as con ocupaciones que les demandan más de seis horas fuera de casa, cuatro de cada diez no pueden evitar asistir a puntos concurridos, hacer uso del transporte público o recibir visitas de personas ajenas a su hogar, siendo que la vivienda es también para muchos de ellos el lugar de trabajo. Más aún, hasta el 50\% reconoce la imposibilidad de mantener un confinamiento estricto y guardar la distancia sugerida en los espacios cotidianos de interacción. 
Como hemos anticipado, las decisiones y estrategias de resguardo frente a la pandemia son indisociables de la tenencia de recursos y posibilidades para esquivar situaciones de riesgo.

CUADRO 7. FACILIDADES Y RECURSOS DISPONIBLES PARA LA GESTIÓN DE LA PANDEMIA, SEGÚN GRUPO ETARIO DE PERTENENCIA (\%)

\begin{tabular}{|c|c|c|c|c|c|}
\hline Recursos/Facilidades & Frecuencia & Hasta 35 & $36-55$ & $\begin{array}{l}56 \text { y } \\
\text { más }\end{array}$ & Total \\
\hline \multirow{4}{*}{$\begin{array}{l}\text { Realizar mi trabajo } \\
\text { desde casa }\end{array}$} & No cuento/No puedo & 73,4 & 74,3 & 35,3 & 68,6 \\
\hline & Difícilmente & 14,5 & 15,2 & 31,4 & 17,2 \\
\hline & \begin{tabular}{|l|} 
Fácilmente/Cuento/Puedo \\
\end{tabular} & 12,1 & 10,5 & 33,3 & 14,2 \\
\hline & \multicolumn{5}{|c|}{ Pearson chi2 $(4)=31,9007 \operatorname{Pr}=0,000$} \\
\hline \multirow{4}{*}{$\begin{array}{c}\text { Comprar mi despensa } \\
\text { desde casa }\end{array}$} & No cuento/No puedo & 74,2 & 74,3 & 47,1 & 70,5 \\
\hline & Difícilmente & 21,0 & 17,8 & 31,3 & 20,8 \\
\hline & \begin{tabular}{|l|} 
Fácilmente/Cuento/Puedo \\
\end{tabular} & 4,8 & 7,9 & 21,6 & 8,7 \\
\hline & \multicolumn{5}{|c|}{ Pearson chi2(4) $=20,1203 \operatorname{Pr}=0,000$} \\
\hline \multirow{4}{*}{$\begin{array}{c}\text { Evitar salir a hacer } \\
\text { trámites }\end{array}$} & No cuento/No puedo & 70,2 & 67,0 & 37,3 & 63,9 \\
\hline & Difícilmente & 26,6 & 29,3 & 49,0 & 31,2 \\
\hline & Fácilmente/Cuento/Puedo & 3,2 & 3,7 & 13,7 & 4,9 \\
\hline & \multicolumn{5}{|c|}{ Pearson chi2(4) $=22,3431$ Pr $=0,000$} \\
\hline \multirow{4}{*}{$\begin{array}{l}\text { Cuento con recursos } \\
\text { para alimentarme } \\
\text { sanamente }\end{array}$} & No cuento/No puedo & 20,2 & 25,2 & 15,7 & 22,2 \\
\hline & Difícilmente & 37,1 & 40,8 & 54,9 & 41,5 \\
\hline & \begin{tabular}{|l|} 
Fácilmente/Cuento/Puedo \\
\end{tabular} & 42,7 & 34,0 & 29,4 & 36,3 \\
\hline & \multicolumn{5}{|c|}{ Pearson chi2 $(4)=7,1082 \operatorname{Pr}=0,130$} \\
\hline \multirow{4}{*}{$\begin{array}{l}\text { Cuento con tiempo } \\
\text { para hacer al menos } \\
30 \text { minutos de } \\
\text { ejercicio diario }\end{array}$} & No cuento/No puedo & 45,2 & 53,4 & 33,3 & 47,8 \\
\hline & Difícilmente & 29,0 & 24,6 & 23,5 & 26,0 \\
\hline & \begin{tabular}{|l|} 
Fácilmente/Cuento/Puedo \\
\end{tabular} & 25,8 & 22,0 & 43,2 & 26,2 \\
\hline & \multicolumn{5}{|c|}{ Pearson chi2 $(4)=11,2446 \operatorname{Pr}=0,024$} \\
\hline \multirow{4}{*}{$\begin{array}{l}\text { En caso de contagio, } \\
\text { cuento con un espacio } \\
\text { para aislarme en casa }\end{array}$} & No cuento/No puedo & 76,6 & 73,3 & 58,8 & 72,4 \\
\hline & Difícilmente & 11,3 & 11,0 & 5,9 & 10,4 \\
\hline & \begin{tabular}{|l|} 
Fácilmente/Cuento/Puedo \\
\end{tabular} & 12,1 & 15,7 & 35,3 & 17,2 \\
\hline & \multicolumn{5}{|c|}{ Pearson chi2 $(4)=14,6095 \operatorname{Pr}=0,006$} \\
\hline \multirow{4}{*}{$\begin{array}{l}\text { Cuento con recursos } \\
\text { para afrontar una } \\
\text { eventualidad médica }\end{array}$} & No cuento/No puedo & 68,6 & 75,4 & 45,1 & 68,9 \\
\hline & Difícilmente & 21,0 & 18,9 & 33,3 & 21,6 \\
\hline & \begin{tabular}{|l|} 
Fácilmente/Cuento/Puedo \\
\end{tabular} & 10,5 & 5,8 & 21,6 & 9,6 \\
\hline & \multicolumn{5}{|c|}{ Pearson chi2 $(4)=20,0006 \mathrm{Pr}=0,000$} \\
\hline \multirow{4}{*}{$\begin{array}{l}\text { Cuento con atención } \\
\text { médica permanente }\end{array}$} & No cuento/No puedo & 66,1 & 33,0 & 19,6 & 42,4 \\
\hline & Difícilmente & 16,1 & 38,2 & 33,3 & 30,1 \\
\hline & Fácilmente/Cuento/Puedo & 17,7 & 28,8 & 47,1 & 27,6 \\
\hline & \multicolumn{5}{|c|}{ Pearson chi2(4) $=50,6247 \mathrm{Pr}=0,000$} \\
\hline
\end{tabular}

Fuente: Elaboración propia.

De ocho aspectos recogidos en nuestro cuestionario de encuesta, siete presentan diferencias significativas entre los distintos subgrupos de edad. Aunque la mayoría de los indicadores tienden a la baja, por la centralidad de la 
muestra en polígonos urbano-populares de la CDMX, los datos del cuadro 7 reflejan que entre las/os jóvenes de menos de 35 años y las/os adultas/os de menos de 56, prevalece una mayor adversidad. Entre estos conglomerados, cerca del $90 \%$ carece de posibilidades para llevar a cabo sus actividades cotidianas desde casa, comprar víveres desde la comodidad del hogar o evitar realizar trámites personales de diversos tipos. En términos de salud, también nueve de cada diez de estas personas no poseen acceso a atención médica ni recursos suficientes para afrontar una eventual enfermedad. Estas parecen ser las verdaderas razones que explican su imposibilidad para acatar las medidas de confinamiento y no una supuesta predisposición a la mayor sociabilidad imputable a su condición etaria.

Como se constata en el gráfico 9, jóvenes y adultos/as de menos de 56 años reportan grados símiles de carencias, mismas que en toda la muestra tienden a variar según la ocupación y la escolaridad máxima alcanzada. Aun entre la población popular encuestada, las distinciones asociadas con los niveles de calidad de vida resultan más evidentes que las propias diferencias de edad. Y es que, de conformidad con algunos apuntes previos, la vasta mayoría (hasta 70\%) de la gente sin educación superior se ve compelida a sostener jornadas laborales que implican pasar más de seis horas fuera del hogar. En el caso de las/os cuentapropistas y de las/os propietarias/os de negocios, sus actividades conllevan a fuertes restricciones para mantener una pauta de confinamiento estricto. 
GRÁFICO 9. TERCILES DEL ÍNDICE FACTORIAL DE RECURSOS Y FACILIDADES PARA GESTIONAR LA PANDEMIA, GRUPO ETARIO, TIPO DE OCUPACIÓN Y ESCOLARIDAD*

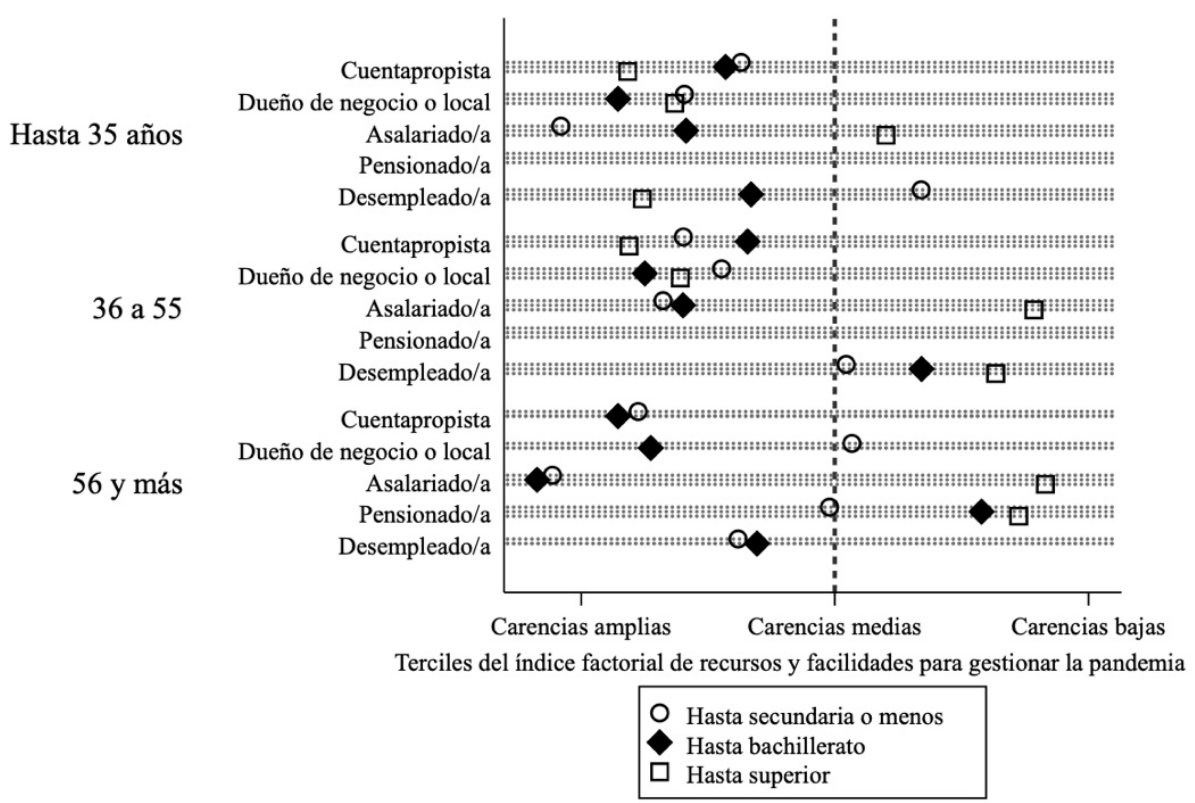

* Índice obtenido por factores principales con retención del 93,04\% de la varianza y KMO de 0,77. La medida sintética se expresa en unidades estandarizadas (media $=0$; desviación estándar=1). Asociación significativa entre el índice de recursos y facilidades para gestionar la pandemia, el tipo de ocupación (Prob $>\mathrm{F}=0,000)$ y la escolaridad (Prob $>\mathrm{F}=0,000)$ mediante ANOVA (Prob $>F=0,000)$. Los grupos de edad (Prob $>F=0,356)$ no exhiben diferencias significativas.

Fuente: Elaboración propia.

Al volver al cotejo entre personas con y sin contagio reportado de Covid19, se hace notar que los rasgos asociados al perfil ocupacional y al tiempo destinado para la realización de actividades económicas fuera de casa son primordiales. Como se recoge en el cuadro 8, hasta cinco de cada diez casos 
contagiados por este virus son de cuentapropistas, y tres de cada diez son de propietarios de negocios o locales.

CUADRO 8. PRINCIPALES RASGOS DE LA MUESTRA SEGÚN CONDICIÓN DE CONTAGIO, GRUPO ETARIO, OCUPACIÓN Y HORAS PROMEDIO FUERA DEL HOGAR $(\%)$

\begin{tabular}{|c|c|c|c|}
\hline & Sin contagio & Con contagio & Total \\
\hline Hasta 35 años & 32,5 & 36,8 & 33,9 \\
\hline 36 a 55 & 50,2 & 56,4 & 52,2 \\
\hline 56 y más & 17,3 & 6,8 & 13,9 \\
\hline \multicolumn{4}{|c|}{ Pearson chi2 $(2)=7,2228 \operatorname{Pr}=0,027$} \\
\hline Cuentapropista & 28,9 & 47,9 & 35,0 \\
\hline Dueño/a de negocio o local & 22,1 & 31,6 & 25,1 \\
\hline Asalariado/a & 20,1 & 19,7 & 20,0 \\
\hline Pensionado/a & 10,4 & 0,0 & 7,1 \\
\hline Desempleado/a & 18,5 & 0,9 & 12,8 \\
\hline \multicolumn{4}{|c|}{ Pearson chi2 $(4)=42,5169 \operatorname{Pr}=0,000$} \\
\hline Hasta 3 horas & 15,7 & 0,9 & 10,9 \\
\hline 4 a 6 horas & 35,7 & 18,8 & 30,3 \\
\hline 7 a 8 horas & 32,1 & 29,1 & 31,2 \\
\hline Más de 8 horas & 16,5 & 51,3 & 27,6 \\
\hline
\end{tabular}

Fuente: Elaboración propia.

Más aún, al volcar la mirada sobre el subgrupo de informantes con prácticas más laxas de prevención y con menor disponibilidad de recursos para afrontar la pandemia, tenemos que las distinciones se suscitan en la recepción de visitas ajenas al hogar y en el uso del transporte público. Más allá de la indisciplina para asumir cautelas sanitarias esenciales, como la portación de mascarillas o los hábitos de higiene personal y familiar, una buena proporción de personas experimenta fuertes dificultades para solventar la recomendación de aislamiento social. Movilizarse al lugar de trabajo, empleando medios de transporte masivos, es una práctica inevitable entre los sectores de menores recursos económicos en la CDMX. 
CuAdro 9. Porcentaje DE PERSONAS CON Y SIN CONTAGIO CON PRÁCTICAS ESPORÁDICAS DE PREVENCIÓN Y BAJA DISPONIBILIDAD DE RECURSOS (\%)

\begin{tabular}{|l|r|r|}
\hline & Sin contagio & $\begin{array}{l}\text { Con } \\
\text { contagio }\end{array}$ \\
\hline & \multicolumn{2}{|c|}{ Nunca/Algo } \\
\hline Portación de cubrebocas en espacios públicos & 25,7 & 22,2 \\
\hline Lavado frecuente de manos & 32,9 & 29,9 \\
\hline Evita reuniones o espacios concurridos & 36,6 & 33,3 \\
\hline Evita salir de casa & 38,6 & 42,7 \\
\hline Practica el distanciamiento social al salir de casa & 41,4 & 43,6 \\
\hline Evita recibir visitas en el hogar & 6,8 & 82,9 \\
\hline Evita hacer uso del transporte público & 8,4 & 75,2 \\
\hline Desinfecta víveres y superficies & 22,1 & 17,1 \\
\hline & No cuento/Difícilmente \\
\hline Realizar mi trabajo desde casa & 81,1 & 95,7 \\
\hline Comprar mi despensa desde casa & 88,0 & 98,3 \\
\hline Evitar salir a hacer trámites & 93,2 & 99,1 \\
\hline Cuento con recursos para alimentarme sanamente & 62,3 & 66,7 \\
\hline Cuento con tiempo para hacer al menos 30 minutos de ejercicio & 67,9 & 86,3 \\
diario & 77,9 & 93,2 \\
\hline En caso de contagio, cuento con un espacio para aislarme en casa & 89,6 & 92,3 \\
\hline Cuento con recursos para afrontar una eventualidad médica & 69,9 & 77,8 \\
\hline Cuento con atención médica permanente & &
\end{tabular}

Fuente: Elaboración propia.

Con esquemas ocupacionales que demandan la prestación de servicios en el propio domicilio (i.e. tiendas, cocinas rápidas, venta de productos, entre otras) o el recorrido de largos desplazamientos hasta el sitio de trabajo, el tiempo opera como un marcador que, aunado a la falta de acceso a seguridad social y servicios médicos, pone en tensión la asunción de cuidados básicos con el acopio de ingresos familiares.

La información analizada muestra que las diferencias en las prácticas de autopreservación no necesariamente pasan por un tamiz distintivo entre jóvenes $\mathrm{y}$ adultos. Por el contrario, y como hemos sostenido, el respeto de tales recomendaciones depende en buena medida de los recursos disponibles. Aun con claras disimilitudes en las percepciones de riesgo a la salud por la Covid-19, el grado de cumplimiento con las acciones para mitigar contagios no es desdeñable. 
Siete de cada diez personas logran proseguir dichos cuidados durante la mayor parte del tiempo. Y, sobre este particular, las prácticas preventivas de los contingentes juveniles no discrepan de lo reportado por la población adulta.

Es evidente que, entre los sectores populares, las labores de manutención y de reproducción del hogar juegan un papel crucial. Sin mayores alternativas para elegir entre confrontarse con mayores privaciones socioeconómicas o asumir los riesgos inherentes de la crisis sanitaria, un volumen importante de personas debe optar por incorporar los peligros de la pandemia en la prosecución de la vida cotidiana. La población juvenil trabajadora no está exenta de velar por el bienestar económico familiar. El cumplimiento de esta responsabilidad es lo que les impide «quedarse en casa». Máxime cuando el gobierno en turno se ha mostrado reticente a activar programas de compensación económica que posibiliten a estos contingentes poblacionales acatar esta recomendación.

\section{A MANERA DE CONCLUSIÓN}

Con base en los patrones de propagación y en los indicios proporcionados por el trabajo emprendido en una muestra situada en localidades populares, hemos constatado que los contingentes juveniles y adultos de menos de 56 años están similarmente expuestos a contagiarse de COVID-19. Esto supone no solo una mejor comprensión de las limitaciones intrínsecas para asumir las principales medidas de mitigación, sino una mejor estrategia de comunicación que, sin estigmas ni juicios sumarios, ayude a comprender los riesgos generales de transmisión del virus SARS-CoV-2.

Es acertado sostener que las personas jóvenes poseen menor propensión al desarrollo de cuadros graves de enfermedad, así como menores posibilidades de mortalidad por contagio de la Covid-19. Empero, dicha tendencia es insuficiente para ignorar que una buena proporción de personas menores de 40 
años fallecen con y sin antecedentes clínicos de comorbilidad. De igual modo, dicha pauta no justifica asumir que la responsabilidad y el compromiso por frenar la enfermedad están exentos de vicisitudes y de contradicciones; la preservación de la salud se pone en entredicho frente a las necesidades ingentes de subsistencia.

Ante los recurrentes señalamientos de displicencia entre las juventudes, nuestros resultados muestran que no existen diferencias significativas entre la población joven y la adulta de cara al acatamiento de la mayoría de las medidas de prevención. Por el contrario, las desigualdades sociales asociadas a la posición ocupacional o la necesidad de salir a trabajar para cubrir el sustento familiar, operan como los factores más relevantes entre quienes pueden atender el llamado al confinamiento domiciliar y quienes deben transitar en los espacios públicos, asumiendo un mayor riesgo de contagio como una fatalidad de su posición social.

Si bien las diferencias por la modalidad de subsistencia parecen caracterizar las estrategias de gestión del riesgo de contagio de COVID-19 entre jóvenes de extracción popular, esto no necesariamente significa que acontezca lo mismo entre juventudes más afluentes. Para establecer una conclusión de más amplio alcance, se requeriría estudiar las prácticas de gestión de grupos más privilegiados frente a la pandemia.

RECIBIDO: 29 DE ABRIL DE 2021 ACEPTADO: 26 DE MAYO DE 2021 


\section{BIBLIOGRAFÍA}

ARAYA, C. ET AL. (2020). Reflexiones sobre la visibilización de lo juvenil por la prensa escrita chilena, en contexto de pandemia. Última Década, 28(53), 5-39. Recuperado el 4 de febrero de 2021 de: https://scielo.conicyt.cl/scielo.php?script=sci arttext\&pid=S071822362020000100005

BAgCCHI, S. (2020). Stigma During the COVID-19 Pandemic. The Lancet. Infectious Diseases, 20(7), 782. Recuperado el 4 de febrero de 2021 de: https://doi.org/10.1016/S1473-3099(20)30498-9

Bargain, O. y UlugbeK, A. (2020). Trust and Compliance to Public Health Policies in times of COVID-19. Journal of Public Economics, 192. Recuperado el 20 de enero de 2021 de: https://www.sciencedirect.com/science/article/pii/S0047272720301808

Chauvin, J. ET AL. (2020). The Younger Age Profile of COVID-19 Deaths in Developing Countries. IBD Working Paper No. IDB-WP-1154. Banco Interamericano de Desarrollo. Recuperado el 4 de febrero de 2021 de: http://dx.doi.org/10.18235/0002879

CHÁvez, V. (2020). López-Gatell: pleitos, curvas y contradicciones. El Financiero. Recuperado el 4 de febrero de 2021 de: https://www.elfinanciero.com.mx/nacional/lopez-gatell-pleitos-curvasy-contradicciones/

Chertorivski, S. ET AL. (2020). La gestión de la pandemia en México. COVID19. Análisis preliminar y recomendaciones urgentes. Consejo Consultivo Ciudadano Pensando en México. Recuperado el 20 de enero de 2021 de: https://es.scribd.com/document/475432014/La-gestion-de-la-pandemiaen-Mexico

Consejo de Evaluación de Desarrollo Social Del Distrito Federal (2010). Medición del Índice de Desarrollo Social de las Unidades Territoriales del DF 2010. Recuperado el 20 de enero de 2021 de: http://data.evalua.cdmx.gob.mx/inicio-medicion-unidadesterritoriales.php

Consulta Mitofsky (2021). El Coronavirus en México. Quincuagésima Tercera Encuesta Nacional. Recuperado el 20 de enero de 2021 de: http://www.consulta.mx/index.php/encuestas-einvestigaciones/item/1425-covid-50

DÍAZ DE RADA, V. (2012). Ventajas e inconvenientes de la encuesta por internet. Papers, 97(1), 193-223. Recuperado el 20 de enero de 2021 de: https://papers.uab.cat/article/view/v97-n1-diaz/pdf 
FEIERSteIn, D. (2021). Pandemia. Un balance social y político de la crisis del COVID-19. Buenos Aires: Fondo de Cultura Económica.

FERRER, A. (2020). AMLO reiniciará giras pese a semáforo rojo nacional. El Financiero. Recuperado el 4 de febrero de 2021 de: http://elfinanciero.com.mx/nacional/amlo-reiniciara-giras-el-1-de-juniocon-visita-a-cancun-quintana-roo/

Furlong, A. y Carmel, F. (2007). Young People and Social Change. Nueva York: McGraw-Hill.

GOBIERNO DE LA CIUDAD (2020). Incrementa gobierno capitalino atención prioritaria por COVID-19 en 200 colonias. Boletín de Prensa 693/2020. Recuperado el 4 de febrero de 2021 de: https:/covid19.cdmx.gob.mx/storage/app/media/uploaded-files/boletin693-incrementa-gobierno-capitalino-atencion-prioritaria-por-covid-19en-200-colonias.pdf

GobIERNO DE MÉXICO (2020a). Medidas de Seguridad Sanitaria. Recuperado el 4 de febrero de 2021 de: https://coronavirus.gob.mx/medidas-deseguridad-sanitaria/

. (2020b). Versión estenográfica de la conferencia de prensa matutina. Lunes 16 de marzo de 2020. Recuperado el 4 de febrero de 2021 de: https://www.gob.mx/presidencia/articulos/version-estenografica-de-laconferencia-de-prensa-matutina-lunes-16-de-marzo-de-2020

HARPER, C. ET AL. (2020). Functional Fear Predicts Public Health Compliance in the COVID-19 Pandemic. International Journal of Mental Health and Addiction, 1-14. Advance online publication. Recuperado el 20 de enero de 2021 de: https://doi.org/10.1007/s11469-020-00281-5

InSTITUTO MEXICANO DE LA JUVENTUd (2017). 18 años al servicio de las y los jóvenes. Comunicado de prensa 2017/B117. Recuperado el 4 de febrero de 2021 de: https://www.gob.mx/imjuve/prensa/imjuve-18-anos-alservicio-de-las-y-los-jovenes-de-entre-12-a-29-anos-de-todo-el-pais

Instituto Mexicano Del Seguro Social, IMSS (2021). Puestos de trabajo afiliados al IMSS. Comunicado de prensa 020/2021. Recuperado el 4 de febrero del 2021 de: http://www.imss.gob.mx/sites/all/statics/i2f_news/PR\%2020.pdf

. (2020). En 2019 se crearon 342 mil empleos. Comunicado de prensa 020/2020. Recuperado el 4 de febrero de 2021 de: http://www.imss.gob.mx/prensa/archivo/202001/020\#: :text=Al\%2031 $\% 20 \mathrm{de} \% 20$ diciembre $\% 202019$, mil $\% 20$ cuatrocientos $\% 20$ cuarenta $\% 20 y$ $\%$ 20dos 
Instituto NACiOnAL DE Estadística Y Geografía (2021). Censo de Población y Vivienda 2020. Recuperado el 4 de febrero de 2021 de: https://censo2020.mx/

Instituto Nacional de SAlud Pública (2020). Encuesta Nacional de Saludy Nutrición COVID-19, ENSANUT. Recuperado el 20 de enero de 2021 de: https://www.insp.mx/avisos/resultados-preliminares-de-la-encuestanacional-de-salud-y-nutricion-covid-

19\#: :text=Los\%20resultados\%20preliminares $\% 20 \mathrm{de} \% 201 \mathrm{a} \% 20 \mathrm{ENSA}$ NUT\%20COVID\%2D19\%20muestran\%20que,de\%20personas\%20a\%2 0nivel\%20nacional

LeVy, E. y SARtorio, L. (2020). Take Me Out: De Facto Limits on Strict Lockdowns in Developing Countries. Covid Economics Vetted and RealTime Papers, Issue 39. London, U.K: Centre for Economic Policy Research. Recuperado el 20 de enero de 2021 de: https://cepr.org/file/9394/download?token=V5WFWAve

Logie, C. y Turan, J. (2020). How Do We Balance Tensions Between COVID19 Public Health Responses and Stigma Mitigation? Learning from HIV Research. AIDS and Behavior, 24, 2003-2006. Recuperado el 4 de febrero de 2021 de: https://link.springer.com/content/pdf/10.1007/s10461-02002856-8.pdf

Machado DA Silva ET AL. (2020). Brazilian Families Facing the COVID-19 Outbreak. Journal of Comparative Family Studies, 54(3-4), 324-336. Recuperado el 4 de febrero de 2021 de: https://www.utpjournals.press/doi/abs/10.3138/jcfs.51.34.008? journalCode $=$ jcfs

MoctezumA, A. (2020). La construcción social del riesgo y del estigma en torno a las pandemias: de la peste negra al COVID-19. Salud Problema, 14(27), 75-93. Recuperado el 4 de febrero de 2021 de: https:/www.clacso.org/wp-content/uploads/2020/11/r-4-863.pdf

ORGANISMO INTERNACIONAL DE JUVENTUD (2008). Convención Iberoamericana de Derechos de los Jóvenes. Recuperado el 4 de febrero de 2021 de: https://oij.org/wp-content/uploads/2017/01/Convenci\%C3\%B3n.pdf

ORGANIZACIÓN DE LAS NACIONES UNIDAS (2020). Cada persona debe asumir la responsabilidad de protegerse del riesgo de contraer el coronavirus. Noticias ONU. Recuperado el 20 de enero de 2021 de: https://news.un.org/es/story/2020/07/1476852

Organización Mundial De LA SAlud (2020). Brote de Enfermedad por Coronavirus (COVID-19): orientaciones para el público. Emergencias Sanitarias. Recuperado el 20 de enero de 2021 de: 
https://www.who.int/es/emergencies/diseases/novel-coronavirus2019/advice-for-public?gclid=EAIaIQobChMIpC40pvi7gIVRzizAB3hBggDEAAYASABEgIcVPD_BwE

Organización PANAmericana de LA SAlud (2020). Algunos países de las Américas muestran picos en la transmisión de la COVID-19, especialmente entre los jóvenes: OPS. Noticias OPS. Recuperado el 4 de febrero de 2021 de: https://www.paho.org/es/noticias/7-10-2020algunos-paises-americas-muestran-picos-transmision-covid-19especialmente-entre

SÁNCHEZ, I. (2020). Reflexiones sobre estigmatización social, desinformación y COVID-19 en México. En C. Pereira ET AL. (coord.), La Pandemia Social de COVID-19 en América Latina. Buenos Aires: Teseo.

Secretaría de SAlud de la Ciudad de MÉXiCo (2021a). Certificados de Defunción de la SEDESA a partir de enero del 2020. Recuperado el 4 de febrero de 2021 de: https://datos.cdmx.gob.mx/dataset/certificados-dedefuncion-sedesa

. (2021b). Reporte de Actas de Defunción. Recuperado el 4 de febrero de 2021 de: https://covid19.cdmx.gob.mx/storage/app/media/Exceso\%20de\%20mort alidad/0502-resumen-ejecutivo-actualizacion-exceso-de-mortalidad-al31-de-enero.pdf

Sistema de Información de Desarrollo Social (2020). Grados de Marginación por Unidad Territorial. Secretaría de Inclusión y Bienestar Social. Recuperado el 20 de enero de 2021 de: http://www.sideso.cdmx.gob.mx/index.php?id=11

Sistema dE VigILANCIA EPIDEMIOLÓGICA DE ENFERMEDAdES RESPIRATORIAS (2021). COVID-19, México: Datos Epidemiológicos. Recuperado el 4 de febrero de 2021 de: https://covid19.sinave.gob.mx/

UNIVERSIDAD IBEROAMERICANA (2020). Encuesta de Seguimiento de los Efectos del COVID en el Bienestar de los Hogares Mexicanos, \#ENCOVID19. UIA/EQUIDE. Recuperado el 20 de enero de 2021 de: https://ibero.mx/sites/default/files/comunicado_encovid19_completo.pdf

VAN Rools, B. ET AL. (2020). Compliance with COVID-19 Mitigation Measures in the United States, Amsterdam Law School Research Paper No. 202021, General Subserie Research Paper No. 2020-03, UC Irvine School of Law Research Paper No. 2020-33. Recuperado el 20 de enero de 2021 de: http://dx.doi.org/10.2139/ssrn.3582626 
Wright, A. ET AL. (2020). Poverty and Economic Dislocation Reduce Compliance with COVID-19 Shelter-in-Place Protocols. Journal of Economic Behavior \& Organization, 180, 544-554. Recuperado el 20 de enero de 2021 de: https://doi.org/10.1016/j.jebo.2020.10.008 